Discussion Paper Series A No.708

Human Capital and Economic Growth in Japan: 1885-2015

\author{
Kyoji Fukao \\ (Hitotsubashi University) \\ Tatsuji Makino \\ (Hitotsubashi University) \\ and \\ Tokihiko Settsu \\ (Musashi University)
}

February 2020

Institute of Economic Research

Hitotsubashi University

Kunitachi, Tokyo, 186-8603 Japan 


\title{
Human Capital and Economic Growth in Japan: 1885-2015
}

\author{
February 2020
}

\author{
Kyoji Fukao (Hitotsubashi University) \\ Tatsuji Makino (Hitotsubashi University) \\ Tokihiko Settsu (Musashi University)
}

\begin{abstract}
This study presents growth account for Japan for the 130 years from 1885 to 2015 based on the measurement of labor quality simultaneously taking the effects of education and the allocation of labor across industries into account. The estimation results indicate that, over the 130 years, Japan's labor productivity rose 46 -fold, with increases in the capital-labor ratio accounting for 40 percent of this rise, improvements in labor quality for 35 percent, and TFP growth for 36 percent. Looking at the periods before and after World War II separately, we found that labor productivity growth accelerated substantially in the postwar period and was twice as high as in the prewar period. This difference in labor productivity growth can be explained by differences in the sources of growth: while growth during the prewar period was driven mainly by improvements in labor quality (with a growth contribution of 37 percent), during the postwar period increases in the capital-labor ratio and TFP growth made the largest contribution (38 percent and 35 percent, respectively).
\end{abstract}




\section{Introduction}

Since Solow's (1957) study suggesting that, according to growth accounting, seven-eighth of the increase in labor productivity in the United States from 1909 to 1949 was due to increases in total factor productivity (TFP) (i.e., the increase in labor productivity minus the contribution of capital deepening), many researchers have made efforts to improve data on the input of factors of production. Since TFP growth is calculated as a residual, it has also been called an indicator of economists' ignorance. However, by taking, for example, increases in labor quality due to the spread of education, fluctuations in working hours, and changes in the quality of capital taking differences in the cost of capital for different types of capital goods into account, economists' degree of ignorance has gradually been whittled away. Through such research, a greater share of economic growth can now be explained by the accumulation of human capital and changes in the composition of capital goods rather than by increases in TFP, fluctuations in which are difficult to account for because it is calculated as a residual.

In particular, measuring labor quality growth has led to a reduction in the growth contribution attributed to TFP growth. Conducting growth accounting for the United States from 1899 onward, Kendrick (1961), based on the idea that inter-industry differences in wages per hour worked reflect inter-industry differences in the marginal contribution of labor to output, regards increases in GDP through faster increases in labor input in high-wage than in low wage industries as increases in labor quality. However, with Kendrick's approach, it is not possible to measure the effect of increases in the level of education within each industry. Meanwhile, Denison (1962) conducted growth accounting in which labor quality growth through education is partly captured through the education premium in wages. These days, growth accounting using industry-level data based on the approach developed by Zvi Griliches and Dale Jorgenson and their colleagues at Harvard University (see, e.g., Jorgenson, Gollop, and Fraumeni, 1987, and Jorgenson, 1995) typically uses information on wage differentials to capture labor quality changes through both the spread of education and the allocation of labor across industries. In this study, following Jorgenson et al. (2007), we refer to this as the "direct aggregation across industries approach" (details of the approach are provided in Section 2). Studies using this approach include Fukao and Miyagawa (2008) for Japan from 1973 onward, Jorgenson, Nomura, and Samuels (2015) for the United States from 1955 onward, and O’Mahony and Timmer (2009) for major advanced economies. ${ }^{1}$

Further, there are a growing number of growth accounting studies based on the measurement of

\footnotetext{
${ }^{1}$ Growth accounting data for developing countries for recent years can be downloaded from the EU KLEMS database (https://euklems.eu/download/). Moreover, more detailed data for Japan can be downloaded from the JIP Database (https://www.rieti.go.jp/en/database/JIP2018/index.html).
} 
labor quality simultaneously taking the effects of education and the allocation of labor across industries into account to examine long-term economic development including the period before World War II. Examples include the studies by Crafts (2019) for the United Kingdom for the period 1700-2016 and Bakker, Crafts, and Woltjer (2019) for the private sector in the United States for the period 1899-1941. (However, for the period before 1856, Crafts (2019) only takes the effect of education levels into account.)

However, there are almost no growth accounting studies for Japan before World War II that simultaneously take education and the allocation of labor across industries into account; studies that do exist consider only one or the other. Major studies that estimated the impact of rising education levels include Ohkawa and Rosovsky (1973, chapter 3) for the period 1901-1963 and Godo and Hayami (2002) for the period 1890-1990. Meanwhile, studies examining the impact of the reallocation of labor across industries include Ohkawa and Rosovsky (1973, chapter 4) covering the period 19051965, Sonobe and Otsuka (2001) covering the non-government sector for the period 1910-1937 and the manufacturing sector for the period 1931-1938, and Fukao, Makino, and Settsu (2019) for the period 1885-1970.

Judging from these previous studies, it appears that the effect of labor reallocation across industries was considerably larger than the effect of rising education levels; however, since the two effects have not been examined in a unified framework, it is difficult to compare the relative size of the effects in detail. Against this background, the current study extends the dataset employed in Fukao, Makino, and Settsu (2019), which conducted growth accounting by dividing the Japanese economy into two sectors, the primary sector and the non-primary sector, by newly adding data on hours worked and wages by education level in the two sectors. The dataset is then used to perform growth accounting using the direct aggregation across industries approach in order to estimate to what extent improvements in labor quality through the reallocation of labor across industries and through factors other than such labor reallocation such as rising education levels, in addition to increases in the capital-labor ratio, contributed to labor productivity growth in the economy overall. Moreover, making use of the advantages of our growth accounting based on a two-sector model, we also examine labor productivity growth in each of the sectors - the primary and the non-primary sector - for the period 1885-1970 by estimating the contribution of changes in the capital-labor ratio and in worker characteristics to growth in real value added. In addition, we examine developments in TFP growth by sector and in the economy overall measured as the residual. A further feature of this study is that we use data from a new set of long-term economic statistics on Japan estimated by a group of researchers based mainly at the Institute of Economic Research, Hitotsubashi University, including the three authors. This allows us to conduct growth accounting for Japan for the period 1885-2015, covering a much longer period 
than in other studies on Japan to date.

As is common in quantitative economic historical research, the more we go back into the distant past, the more difficult it is to obtain detailed data on par with data available for more recent years. For this reason, Crafts (2019) in his study uses data with different degrees of aggregation and accuracy for different periods and examines long-term developments in the UK economy by linking the results for the different periods. We follow this approach. While details of the data are presented in Section 3 and the Appendix, let us provide a brief sketch here. For 1885-1955, we use data dividing the economy overall into the primary and the non-primary sector. The main reason that we divide the economy only into two sectors is that for the period before World War II, detailed industry-level data are not available. For 1955-1970, we use data dividing the macroeconomy into 24 industries. For 1970-1995, we use the Japan Industrial Productivity Database 2015 (JIP 2015), which divides the economy into 108 industries, while for 1995-2015, we use the JIP Database 2018 (JIP 2018), which divides the economy into 100 industries. By linking these data in 1955, 1970, and 1995, we are able to create a dataset that covers the period 1885-2015.

Because we link our data, there is a risk that there might be discontinuities in the results of the growth accounting analysis. The most important issues probably are the following two types of discontinuity. First, when the rate of labor input growth is higher in high-wage industries than in lowwage industries, the coarser the industry classification, the more the effect of labor quality growth through labor reallocation will be underestimated and TFP growth correspondingly be overestimated. Conversely, when the rate of labor input growth is higher in low-wage industries than in high-wage industries, the coarser the industry classification, the more the effect of labor quality growth through labor reallocation will be overestimated and TFP correspondingly be underestimated. For example, in our growth accounting for the period up to 1955, non-primary industries are regarded as one sector. Therefore, GDP growth through a higher growth rate of workers with a given level of education in high-wage industries in the non-primary sector (e.g., finance and insurance) than in low-wage industries (e.g., restaurants) will be measured as TFP growth. In contrast, since the growth accounting for the period from 1955 onward distinguishes between the restaurant industry on the one hand and finance and insurance on the other, this labor reallocation effect is included in the increase in labor quality, so that TFP growth will be correspondingly lower.

Second, our data from 1995 onward (from the JIP 2018) is based on the 2008 system of national accounts (SNA), in which research and development (R\&D) is regarded as gross capital formation. This means that for the period from 1995 onward, the estimated contribution of increases in the capitallabor ratio is larger and the estimated contribution of TFP growth consequently smaller than in the 
period before 1995.

In addition to the above-mentioned discontinuities, in the period up to 1955, only the education level is considered as an industry-specific worker characteristic; however, for the period from 1955 onward, differences in labor quality reflecting characteristics such as workers' employment status, sex, age (and the accumulation of skills associated therewith), etc., are considered. For this reason, it should be noted that the effect of "increases in labor quality other than through the reallocation across industries" refers only to the effect of education before 1955 but includes the effect of changes in these other characteristics as well as education after 1955. This issue will be discussed in detail in Sections 2 and 3.

The remainder of the study is organized as follows. The next section outlines the growth accounting approach and data used in this study. Section 3 then reports the results of the growth accounting analysis. In particular, the analysis focuses in detail on the effects of improvements in labor quality on labor productivity and the causes of labor quality growth. The analysis highlights that during the period before World War II, rising education levels made a major contribution to labor quality growth, while during the high-speed growth era, the reallocation of labor across industries played a major role. Section 4 summarizes the results obtained in this study. Finally, Appendix 1 provides details of the data used.

\section{Growth accounting approach and data}

This section explains the theoretical framework of our growth accounting analysis. As mentioned in Section 1, the more recent the period, the more detailed the data that are available, so that we need to make fewer assumptions for the growth accounting analysis. We start by presenting the theoretical framework for the growth accounting for the period 1885-1955, followed by the framework for the period from 1955 onward.

Assume that the economy consists of a primary and a non-primary sector. Real value added $V_{A}(t)$ in the primary sector in year $t$ depends on the combination of capital input $K_{A}(t)$, land input $Z_{A}(t)$, and various types of labor input (measured in hours worked), $H_{A, 1}(t), \cdots H_{A, j}(t), \cdots H_{A, J}(t)$, and a productivity index $T_{A}(t)$ that reflects the level of technology and the efficiency of resource allocation within the primary sector. This relationship is expressed by the following production function:

$$
V_{A}(t)=G_{A}\left(K_{A}(t), Z_{A}(t), H_{A, 1}(t), \cdots H_{A, j}(t), \cdots H_{A, J}(t), T_{A}(t)\right)
$$


For the non-primary sector, it is assumed that the impact of land input on output is negligible, and real value added $V_{N}(t)$ is given by the following equation:

$$
V_{N}(t)=G_{N}\left(K_{N}(t), H_{N, 1}(t), \cdots H_{N, j}(t), \cdots H_{N, J}(t), T_{N}(t)\right)
$$

where subscript $N$ denotes values for the non-primary sector.

We assume that in the above production functions inputs of capital, land, and labor are separable. Using the aggregate indexes of labor input $L_{A}\left(H_{A, 1}(t), \cdots H_{A, j}(t), \cdots H_{A, J}(t)\right)$ and $L_{N}\left(H_{N, 1}(t), \cdots H_{N, j}\right.$ $\left.(t), \cdots H_{N, J}(t)\right)$, the relationship between the production functions can be expressed as follows:

$$
\begin{aligned}
& V_{A}(t)=F_{A}\left(K_{A}(t), Z_{A}(t), L_{A}\left(H_{A, 1}(t), \cdots H_{A, j}(t), \cdots H_{A, J}(t)\right), T_{A}(t)\right) \\
& V_{N}(t)=F_{N}\left(K_{N}(t), L_{N}\left(H_{N, 1}(t), \cdots H_{N, j}(t), \cdots H_{N, J}(t)\right), T_{N}(t)\right)
\end{aligned}
$$

Assuming that firms as well as those in agriculture, forestry, and fishery engage in cost minimization given factor prices in factor markets (and assuming that labor input (hours worked) even of the selfemployed and unpaid family workers is determined by taking the opportunity cost of supplying labor into account), that the production functions are sufficiently smooth, and that there are no large jumps in relative prices over time, the growth rate of real value added in sector $i(i=A, N)$ from year $t$ to year $t+1$ can be approximated by the following equations (for details, see Fukao et al., 2007):

$$
\begin{aligned}
& \widehat{V}_{A}=\overline{s_{K, A}} \widehat{K}_{A}+\overline{s_{Z, A}} \hat{Z}_{A}+\overline{s_{L, A}} \widehat{L}_{A}+\widehat{\Omega}_{A} \\
& \widehat{V}_{N}=\overline{s_{K, N}} \widehat{K}_{N}+\overline{s_{L, N}} \widehat{L}_{N}+\widehat{\Omega}_{N}
\end{aligned}
$$

where $s_{m, i}$ represents the income share of factor $m$ in sector $i$ (the share of factor income in gross value added) and $s_{K, A}{ }^{+} S_{Z, A}+s_{L, A}=1$ and $s_{K, N}+s_{L, N}=1$ hold. Variables with an upper bar denote the average of the values of that variable in years $t$ and $t+1$. Note that subscript $t$ for the year is suppressed in order to simplify the notation. $\wedge$ represents the logarithmic growth rate. For example, the left-hand side of Equation (3) represents $\ln \left(V_{A}(t+1)\right)-\ln \left(V_{A}(t)\right) . \Omega_{i}$ is an index representing the TFP level in sector $i$, and the relationship between $\Omega \mathrm{i}$ and the productivity index $T_{i}(i=A, N)$ is given by the following equation:

$$
\widehat{\Omega}_{i}=\frac{\frac{\partial F_{i}}{\partial T_{i}}}{F_{i}(\cdot)} \widehat{T}_{i}
$$


The growth rate of the labor input index $L_{i}(i=A, N)$ in Equations (3) and (4) is defined by the following equation:

$$
\widehat{L}_{i}=\sum_{j} \overline{\omega_{l, j}} \widehat{H}_{i, j}
$$

where $\omega_{j, i}$ represents the cost share of labor type $j$ in the total labor costs in industry $i$. This kind of index is called a Törnqvist approximation of the Divisia index (see chapter 1 in Fukao and Miyagawa, 2008). The labor input index $L_{i}$ represents the labor input when assuming that the wage differential between different types of labor represents the difference in the contribution of each type of labor to output (this necessarily holds under our assumptions regarding cost minimization), that is, when differences in labor quality are taken into account.

By subtracting the growth rate of total hours worked $H_{i}$ in each sector from both sides of Equations (3) and (4), the following growth accounting equations for the labor productivity growth rate in each of the two sectors can be derived:

$$
\begin{aligned}
& \widehat{V}_{A}-\widehat{H}_{A}=\overline{s_{K, A}}\left(\widehat{K}_{A}-\widehat{H}_{A}\right)+\overline{s_{Z, A}}\left(\hat{Z}_{A}-\widehat{H}_{A}\right)+\overline{s_{L, A}}\left(\widehat{L}_{A}-\widehat{H}_{A}\right)+\widehat{\Omega}_{A} \\
& \widehat{V}_{N}-\widehat{H}_{N}=\overline{s_{K, N}}\left(\widehat{K}_{N}-\widehat{H}_{N}\right)+\overline{s_{L, N}}\left(\widehat{L}_{N}-\widehat{H}_{N}\right)+\widehat{\Omega}_{N}
\end{aligned}
$$

The left-hand side of Equation (6) represents the growth rate of labor productivity (real value added per hour worked), $V_{A} / H_{A}$, in the primary sector. The first and second terms on the right-hand side respectively represent the impact of increases in the capital-labor ratio per hour worked, $K_{A} / H_{A}$, and in the land-labor ratio, $Z_{A} / H_{A}$, on labor productivity in the primary sector. In the third term on the right-hand side, the difference between the growth rate of the labor input index $L_{A}$ and the growth rate of total hours worked, $H_{A}$, represents the increase in labor quality in the primary sector. The last term on the right-hand side is the TFP growth rate, which is calculated as the residual, that is, the difference between the growth rate of labor productivity on the left-hand side and the contribution of the other three terms on the right-hand side related to the three production factors.

Finally, the real value added in the economy overall (GDP), $V$, is defined by the following equation, which is a Törnqvist approximation of a Divisia index consisting of the weighted average of the real value-added growth in the two sectors:

$$
\widehat{V}=\sum_{i} \bar{\nu}_{l} \widehat{V}_{i}
$$


where $v_{i}$ represents the share of sector $i$ 's nominal value added in nominal GDP. ${ }^{2}$

Substituting Equations (3) and (4) into the right-hand side of Equation (8) and subtracting the growth rate of hours worked in the economy overall, $H$, from both sides, the following growth accounting equation can be derived:

$$
\begin{aligned}
\widehat{V}-\widehat{H}= & \left\{\bar{v}_{A} \overline{S_{K, A}} \widehat{K}_{A}+\bar{v}_{N} \overline{S_{K, N}} \widehat{K}_{N}-\left(\bar{v}_{A} \overline{S_{K, A}}+\bar{v}_{N} \overline{S_{K, N}}\right) \widehat{H}\right\}+\bar{v}_{A} \overline{S_{Z, A}}\left(\hat{Z}_{A}-\widehat{H}\right)+ \\
& \left\{\bar{v}_{A} \overline{S_{L, A}} \widehat{L}_{A}+\bar{v}_{N} \overline{S_{L, N}} \widehat{L}_{N}-\left(\bar{v}_{A} \overline{S_{L, A}}+\bar{v}_{N} \overline{S_{L, N}}\right) \widehat{H}\right\}+\left(\hat{v}_{A} \widehat{\Omega}_{A}+\hat{v}_{N} \widehat{\Omega}_{N}\right)
\end{aligned}
$$

The four terms on the right-hand side of this equation show the labor productivity growth in the economy overall as a result of increases in the capital-labor ratio, the land-labor ratio, labor quality, and TFP in the economy overall. The last term is the average of the TFP growth rates in the two sectors weighted by the value added shares of the two sectors. The term representing the contribution of labor quality growth in the above equation can be decomposed into the contribution of labor quality growth in the economy overall through the reallocation of labor across industries and the contribution of other effects such as education and other changes in worker characteristics apart from the industry in which they work. This can be shown as follows. Using Equation (5) and the fact that the labor income share in the economy overall is $v_{A} S_{L, A}+v_{N} S_{L, N}$, the third term on the right-hand side of Equation (9) can be transformed as follows:

$$
\begin{aligned}
& \left\{\bar{v}_{A} \overline{S_{L, A}} \hat{L}_{A}+\bar{v}_{N} \overline{S_{L, N}} \hat{L}_{N}-\left(\bar{v}_{A} \overline{S_{L, A}}+\bar{v}_{N} \overline{L_{L, N}}\right) \widehat{H}\right\}=\left(\bar{v}_{A} \overline{S_{L, A}}+\bar{v}_{N} \overline{S_{L, N}}\right)\left\{\sum_{j} \sum_{i}\left(\overline{\frac{w_{l, J} H_{l, J}}{\sum_{J} \sum_{l} w_{l, J} H_{l, J}}} \widehat{H}_{i, j}\right)-\widehat{H}\right\} \\
& =\left(\bar{v}_{A} \overline{s_{L, A}}+\bar{v}_{N} \overline{S_{L, N}}\right)\left[\left\{\sum_{j}\left(\overline{\frac{\sum_{l} w_{l, J} H_{l, J}}{\sum_{J} \sum_{l} w_{l, J} H_{l, J}}} \widehat{H_{J}}\right)-\widehat{H}\right\}\right.
\end{aligned}
$$

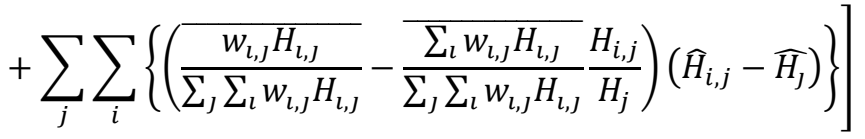

The second term in large brackets represents the increase in labor quality as workers with a particular characteristic are reallocated from the sector that pays lower wages for that characteristic to that with

\footnotetext{
${ }^{2}$ In order for the following equations to strictly hold, $v_{i}$ needs to be the gross added value share of industry $i$ in GDP at factor prices (i.e., GDP at market prices plus subsidies minus indirect taxes). However, because it is difficult to obtain industry/sector-level data for gross value added at factor prices for the period before 1955, we use the share of each sector in GDP at market prices instead, assuming that the ratio between the gross value added at factor prices and at market prices is the same for the two sectors.
} 
higher wages for that characteristic. In the following, this is referred to as "increases in labor quality due to the reallocation across sectors." The first item in large brackets represents the increase in labor quality through changes in hours worked of workers with certain characteristics other than the industry/sector in which they work. This is measured by evaluating the contribution of workers with characteristic $j$ other than the industry/sector in which they work to output using the average wage in the overall economy for workers with characteristic $j$. In the following, this is referred to as "increases in labor quality through changes other than the reallocation of labor." Since for the period before 1995 the only data available for worker characteristics is the level of education (measured by last school attended) and the industry in which they work, "increases in labor quality through changes other than the reallocation of labor" represent the effect of the education level.

Next, we outline our approach to estimating labor input in the prewar period. Ideally, we would estimate labor input by industry/sector and by sex; however, because the necessary data are not available, we do not estimate labor input by sex for the prewar period. As mentioned earlier, in this study, we estimate labor input for the primary and non-primary sector. To that end, it is necessary to estimate hours worked and labor quality (education level) by sector. We start by describing our estimation of hours worked.

For hours worked in the prewar period, we use data compiled by the Nihon Rodo Undo Shiryo Iinkai [Japan Labor Movement Historical Documents Committee] (1959). The book includes data on hours worked and days worked in the manufacturing sector overall and by industry from 1923 onward, and we use these data to calculate the annual hours worked in the manufacturing sector overall. For the period before 1923, we use data on hours and days worked for cotton spinning mills from 1887 to 1921. However, the hours worked in these data are around 20 hours per day in most years, so that the figures probably refer to operating hours. We therefore divide the figures by two based on the assumption of two shifts. From 1918 to 1921, hours worked are much shorter, but since we do not know whether this means that operating hours decreased, or whether the way that data were collected changed and what represented operating hours until then changed to actual hours worked, we calculate the annual hours worked assuming that hours worked uniformly were 10 hours a day. Further, to link the data up to 1921 with the data from 1923 onward, we calculate the ratio of the average annual hours worked from 1926 to 1930 to the average annual hours worked in the manufacturing sector overall for the same period (0.94) and multiply the data for cotton spinning mills before 1921 by this ratio. For 1922, for which no data are available, we estimate the data using linear interpolation, while for 1885 and 1886, we use the average for the three years from 1887 to 1889. As can be seen in Figure 1, our estimates show a gradual uptrend in hours worked during this period. 
We regard the hours worked series for the manufacturing sector thus obtained as the hours worked in the secondary sector and obtain the hours worked series for the primary and tertiary sectors by multiplying this series by a fixed ratio. Based on data from a survey in 1941 published in Nihon Hoso Kyokai [Japan Broadcasting Corporation] (1990), for primary sector hours worked we multiply the series for the manufacturing sector by a factor of 1.01, while for hours worked in the tertiary sector, we use the ratio of hours worked in the secondary sector to hours worked in the service sector from Minami and Ono (1975), which is 1.03.

Figure 1. Annual hours worked in the manufacturing sector, 1885-1940 (hours)

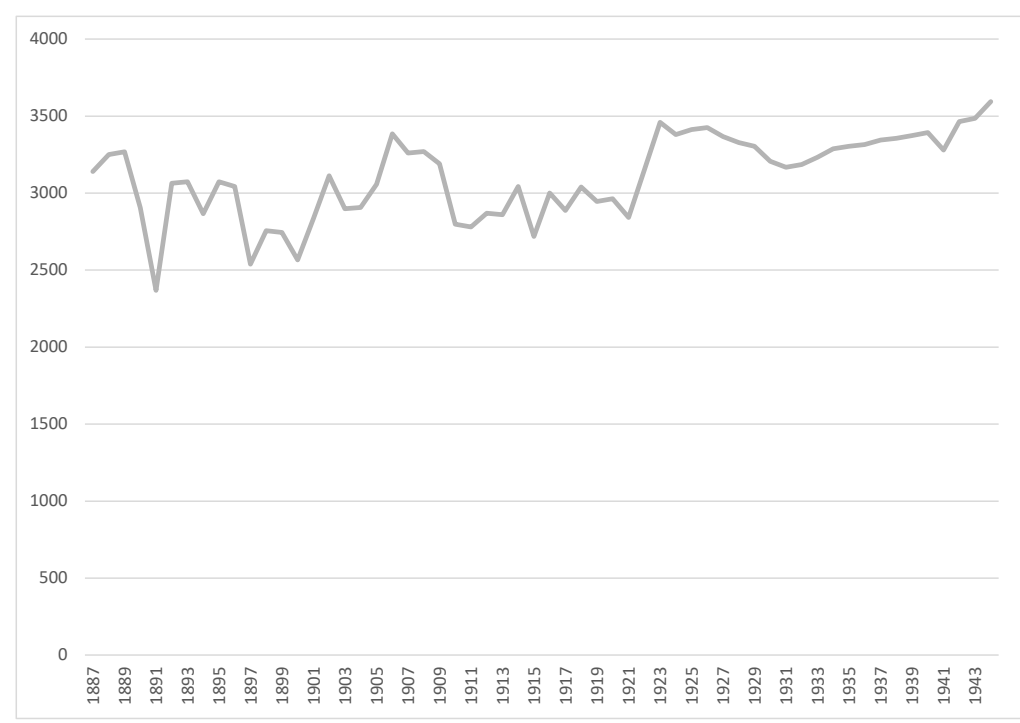

Source: See text.

Next, we calculate man-hours by multiplying the sector-level hours worked thus obtained by the sector-level labor force. For the labor force, we use the data from appendix table 2 in Fukao, Settsu, and Nakabayashi (2018) and appendix table 2 in Fukao and Settsu (2018a).

Figure 2. Man-hours by sector (million workers $\times$ hours worked) 


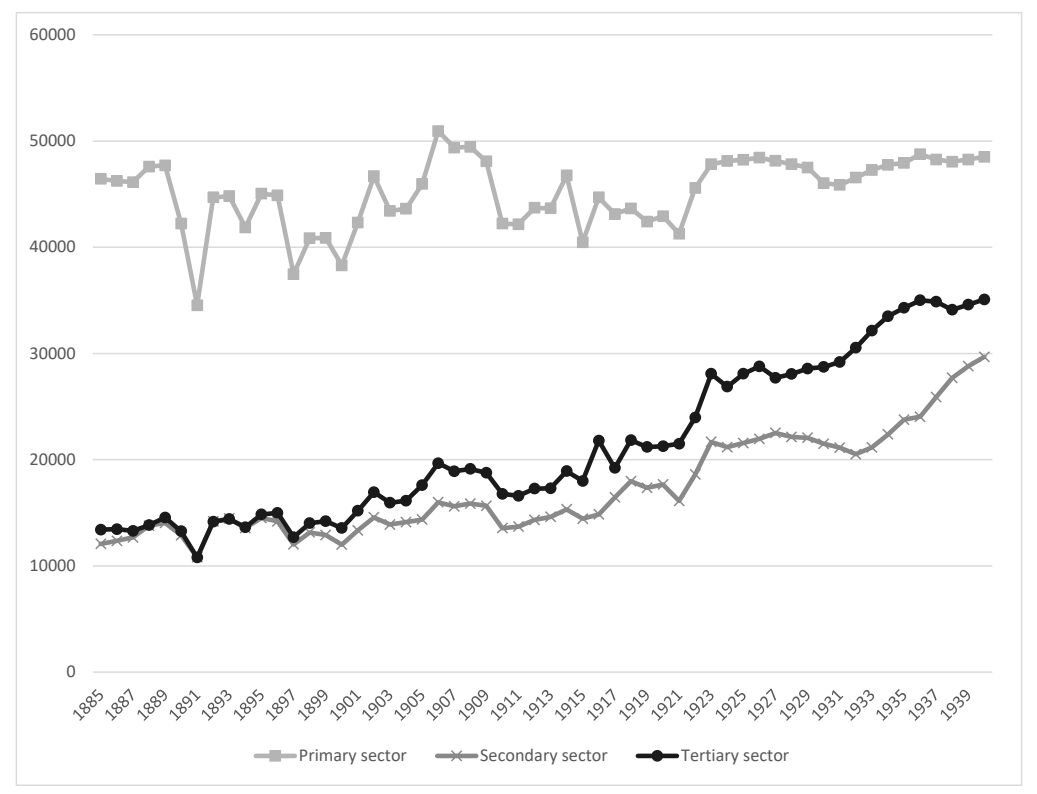

Source: See text.

For data on labor quality in the economy as a whole, we use the estimates of the population share by educational attainment for the population aged 15-64 by Lee and Lee (2016). ${ }^{3}$ These data provide estimates of the working-age population share by educational attainment (four levels: no schooling, primary, secondary, and tertiary), and by multiplying these with figures for the population aged 15 and over taken from Umemura et al. (1988), we calculate the population by educational attainment. As the next step, we need to allocate the population by educational attainment to the primary and the nonprimary sector. Since data for the prewar period data on educational attainment by industry are unavailable, we use postwar census data. Specifically, we use the educational attainment shares in urban areas for the non-primary sector and the educational attainment shares for rural areas for the primary sector.

We start by calculating the educational attainment share in urban and rural areas for the population aged 15 to 64 by age group (for cohorts in five-year intervals) using the data from the 1960 Population Census, which provides data for school attendance (three groups), graduates' educational attainment (eight groups), age (in five-year intervals), and the population aged 6 years and above by sex in Japan as a whole, in urban areas, and in rural areas. We then extrapolate backward shifting the cohort every five years. ${ }^{4}$ Doing so, we can extrapolate backward to 1935, when we can no longer obtain data for

3 The dataset of Lee and Lee (2016) can be downloaded at http://barrolee.com/Lee_Lee_LRdata.htm.

${ }^{4}$ The data are taken from table 6 of Statistics Bureau, Prime Minister's Office (1964). We regard elementary and higher elementary schools as primary education, youth schools and former junior high schools as secondary education, and former high schools (including junior colleges) and universities as tertiary education. For the population by age group, we use table 4 in Okazaki (1986) for the period 1885-1915 and table 2-3 in Japan Statistical Association (2006), Volume 1. 
the cohort of 60-64 year-olds, so that we substitute the data for that cohort with data for those aged 55-59. We use the same methodology to calculate backwards to 1885.

Next, using the population by age for each year as weights, we take the weighted average of the urban and rural population composition by age and educational attainment thus calculated for every five years from 1885 to obtain the educational composition in urban and rural areas. ${ }^{5}$ Furthermore, using the population shares by educational attainment thus obtained, we divide the population by educational attainment estimated earlier into urban and rural areas and regard the population composition by educational attainment in urban areas as the composition of workers by educational attainment in the non-primary sector and that in rural areas as that in the primary sector, and divide the labor force in each industry by educational attainment.

Figure 3. Educational composition of workers in the primary sector (1885-1940)

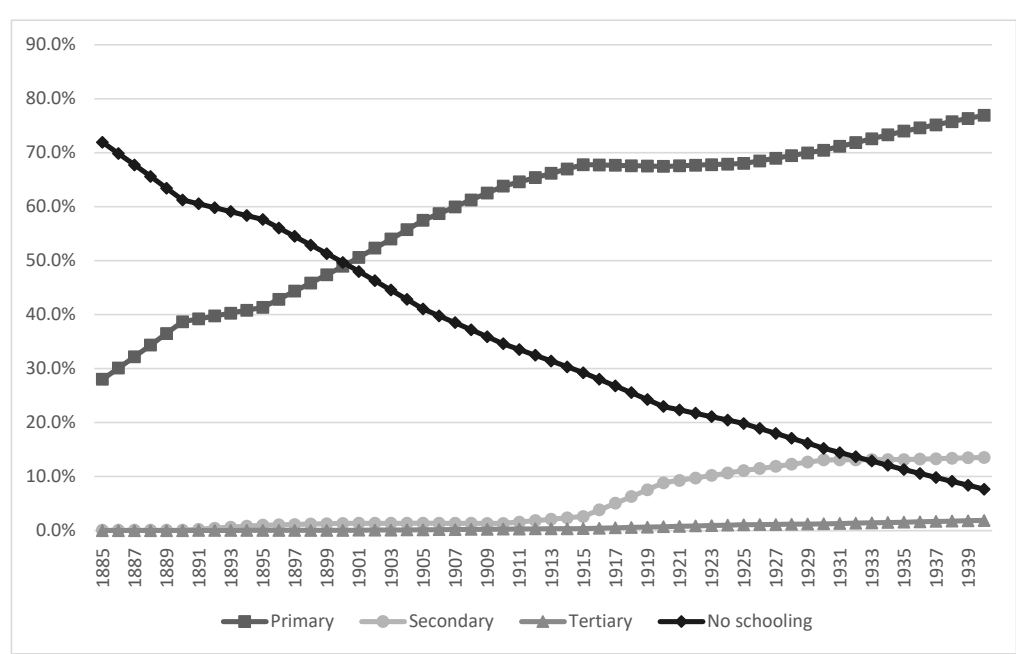

Source: See text.

Note: Primary education refers to elementary and higher elementary schools, secondary education to youth schools and former junior high schools, and tertiary education to former high schools (including junior colleges) and universities.

Figure 4. Educational composition of workers in the non-primary sector (1885-1940)

\footnotetext{
${ }^{5}$ For the population by age group, we use table 4 in Okazaki (1986) for the period 1885-1915 and table 23 in Japan Statistical Association (2006), Volume 1.
} 


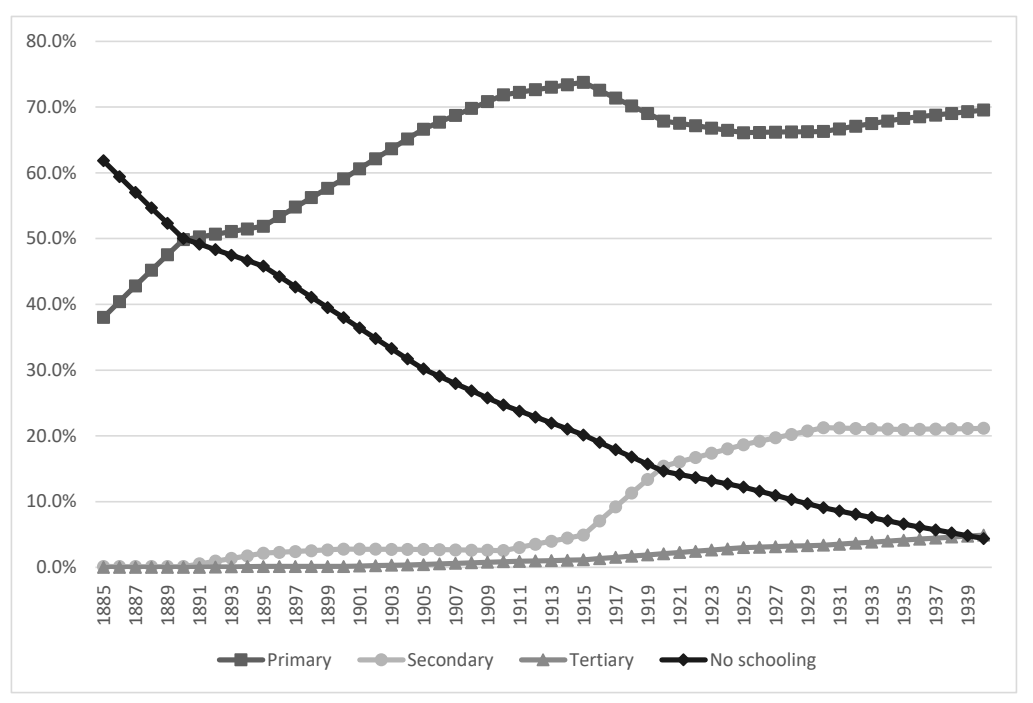

Source: See text.

As shown in Figures 3 and 4, our estimation shows that the percentage of those without schooling declined rapidly over time in both the primary and the non-primary sector. The main difference between the two sectors is the ratio of those with secondary education after the outbreak of World War I, which increased markedly in the non-primary sector.

Next, in order to see how much productivity changed due to changes in the composition of workers' educational attainment, we consider the wage gap between workers with different levels of educational attainment. Since data covering all sectors and years are not available, we use wage data for civil servants. Specifically, we use the Annual Report of the Ministry of Education, which is available annually and provides information on the annual or monthly wage and the number of employees by position chokuninkan (imperial appointees), soninkan (higher ranking officials appointed by the prime minister), hanninkan (junior officials), and employees. Using these data, we obtain the annual income per worker by position and then calculate the differentials by regarding the income of soninkan (higher ranking officials) as representing the wage of tertiary education graduates, that of hanninkan (junior officials) as representing the wage of secondary education graduates, and that of employees as representing the wage of primary education graduates. Moreover, using the estimates of Ohkawa and Rosovsky (1973), we assume that the wage of those without schooling was 0.748 times that of primary education graduates. ${ }^{6}$

Figure 5. Developments in wage differentials (1885-1940)

\footnotetext{
${ }^{6}$ More specifically, we use the index of wage differentials by sex and education level on page 72 of Ohkawa and Rosovsky (1973) to obtain the weighted average using the number of those without schooling by sex calculated from the data on the composition of the working age population by educational attainment (in 1935) from table 3-6 in Ohkawa and Rosovsky (1973) as weights.
} 


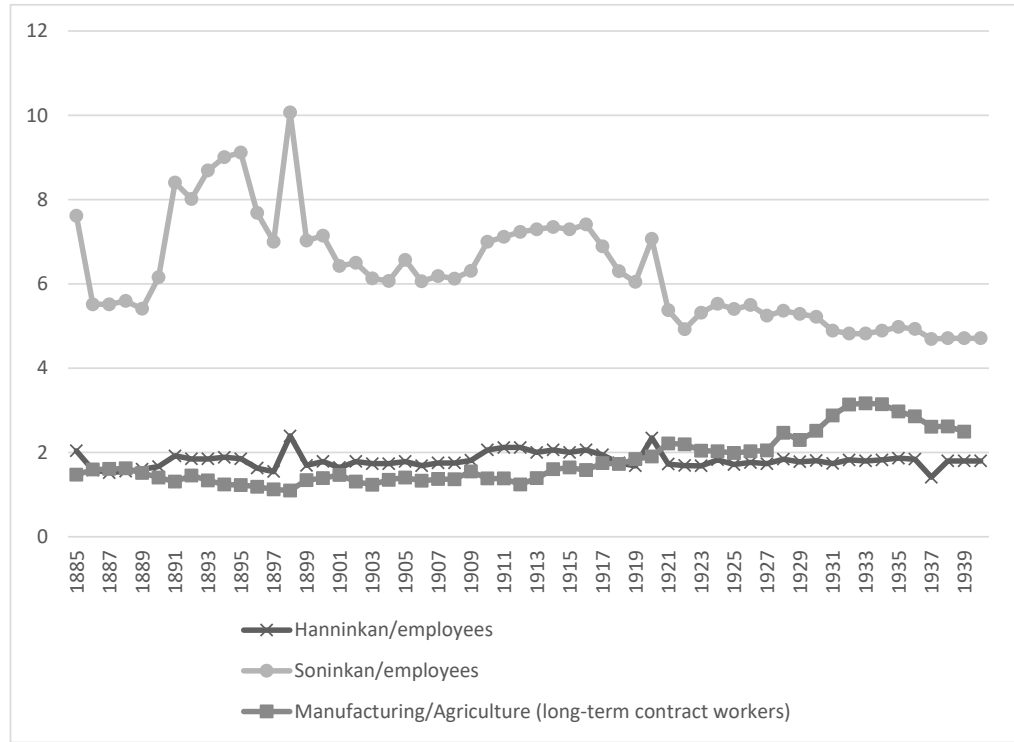

Source: See text.

As references wages, for elementary education graduates in the primary sector we use the wages of long-term contract workers in agriculture from Umemura et al. (1966), and for elementary education graduates in the non-primary sector we use the manufacturing sector wages (daily wages) from Ohkawa et al. (1967) and convert these into annual wages by multiplying the figures by 27 (days) and 12 (months). In addition, we adjust the total wages in each sector to match the labor costs in that sector obtained by multiplying the sector-level GDP by the labor income share of that sector. ${ }^{7}$ Finally, we calculate macro-level wages by educational attainment as the weighted average of the values for each sector using the number of workers in each sector and for each educational attainment level as weights.

As mentioned earlier, since for the period from 1955 more detailed data are available, we use a different growth accounting approach. For 1955-1970, we construct data for 24 industries (details of how we construct the main data up to 1970 are provided in the Appendix). For 1970-1995, we use the JIP 2015 for 108 industries, and for 1995-2015, we use the JIP 2018 for 100 industries. The following points should be noted concerning differences in the approach and data used for each of the periods and the expected impact of these differences. (For details of the overall approach, see chapter 1 in Fukao and Miyagawa, 2008).

First, the degree to which industry classifications are aggregated differs. As explained in Section 1, changes in the level of detail of the industry classification may affect the size of the labor reallocation effect and TFP growth. Moreover, whereas real value added by industry is, in principle, calculated on the basis of fixed prices of a reference year (for example, on the basis of 1935 prices for the period before World War II), GDP is measured as an index using Törnqvist approximation of the Divisia

\footnotetext{
${ }^{7}$ For details on the labor income share in each sector, see the Appendix.
} 
index, as in Equation (8). This can lead to various measurement issues. For example, in the case of industries such as the heavy and chemical industries and information and communication technology (ICT) goods producing industries, where technological innovation is rapid and product prices fall quickly, if the price elasticity of demand is less than 1, the share of these industries in nominal GDP will decline even if real output increases (the Baumol effect). If such a mechanism is at work, the more detailed the industry classification, the more this effect will be captured. Meanwhile, while we take land input (arable land area) into account in the growth accounting for the primary sector for the period before 1970, since the primary sector during this period still accounted for a large share of the economy overall, in the period from 1970 onward we do not take land input into account. Therefore, we present growth accounting in which we divide the economy into the primary and the non-primary sector only up to 1970 , and for the period after that we report only the results for the macroeconomy as a whole.

Second, the level of detail of worker characteristics captured by the data differs. For the period from 1955 onward, data on hours worked and wages classified by worker characteristics include as categories workers' employment status (employee or self-employed/unpaid family worker and, from 1970 onward, whether they are a regular or non-regular employee), their sex, and their age. Therefore, for this period, "the effect of labor quality improvements other than through the reallocation of labor across industries" includes not only the impact of education but also the impact of changes in the employment status, in the share of women in employment, and the accumulation of skills.

Third, the information on capital goods captured by the data differs. From 1955, data on the capital stock and the cost of capital by type of capital good are available, so that we measure capital input in terms of the capital services input index (see footnote 1), meaning that the contribution of increases in the capital-labor ratio include the effect of increases in the quality of capital. Therefore, the estimates of TFP growth are also affected.

\section{Growth accounting results}

This section presents our growth accounting results. Using Equations (6) and (7) for the primary and non-primary sectors and Equation (9) for the economy overall, Table 1 shows the labor productivity growth (real value added per hour worked) decomposed into the contribution of the sources of growth seen from the supply side. For the primary sector and the economy overall, these are the contribution of increases in the capital-labor ratio (capital stock per hour worked), increases in the land-labor ratio (arable land area per hour worked), increases in labor quality, and TFP growth, while for the non-primary sector, these are the same factors except for the land-labor ratio. The sum 
of increases in hours worked and labor productivity growth equals the growth in real value added (real GDP growth in the case of the economy overall). Table 1 therefore also shows the growth rates of hours worked and real value added. All rates of increase are the average annual rate over the period measured in terms of the logarithmic growth rate (the change in the logarithm over time). The growth accounting for the two sectors is conducted for the period up to 1970, when the primary sector still accounted for a sufficiently large share of the economy overall.

To provide a visual impression, Figure 6 shows the results of this growth accounting for the economy overall. Meanwhile, Figures 7 and 8 show the sources of labor productivity growth from 1885 onward in the form of cumulative values for the economy overall and for the two sectors. Since the figures show the cumulative value in natural logarithm, the value of 3.82 for labor productivity in 2015 shown in Figure 7, for example, means that labor productivity during the period 1885-2015 increased by a factor of $46\left(2.72^{3.82}=46\right)$. Further, in order to link the results for the two sectors with developments in the economy overall, Figure 9 shows the shares of the two sectors in the total hours worked in the economy overall and in nominal GDP.

In the 130 years from 1885 to 2015, labor productivity (in 2015 prices) increased 46 times from 87 yen to 4,000 yen per hour, and according to Figure 39 percent of this increase is due to increases in the capital-labor ratio, 25 percent due to increases in labor quality, and 36 percent due to TFP growth. Dividing the period overall into the period before and the period after World War II, we find that labor productivity increased 3.3 times in the 55 years from 1855 to 1940, while it increased 10.2 times in the 60 years from 1955 to 2015. Looking at the annual average growth rate of labor productivity and the contribution of the three factors in these two periods, we find that labor productivity grew at an annual average rate of 2.2 percent in the period 1885-1940, of which increases in the capital-labor ratio contributed 0.70 percentage points, increases in labor quality 0.81 percentage points, and TFP growth 0.71 percentage points (so that the shares of the growth contributions are 32 percent, 37 percent, and 32 percent, respectively). Meanwhile, in the period 1955-2015, the labor productivity growth rate was 3.9 percent, with increases in the capital-labor ratio contributing 1.66 percentage points, increases in labor quality 0.72 percentage points, and TFP growth 1.53 percentage points (shares: 42 percent, 18 percent, and 39 percent, respectively). The share of the contribution of changes in the land-labor ratio to labor productivity growth was less than 1 percent in both periods.

Thus, the results indicate that labor productivity growth in the prewar period was led by improvements in labor quality, while in the postwar period it was led by capital accumulation and TFP growth. Further, compared to the prewar period, labor productivity growth in the postwar period was almost twice as high, which was due to the fact that increases in the capital-labor ratio were 2.4 times 
as high and TFP growth 2.2 times as high. On the other hand, the pace of increase in labor quality in the postwar period was only 0.89 times of that in the prewar period.

Looking at the results for the two sectors, the non-primary sector includes modern industries such as the heavy and chemical industries and transportation and communication, which are capital intensive and characterized by rapid technological innovation. Reflecting this, the growth accounting for the two sectors shows that the non-primary sector made a larger contribution to TFP growth and increases in the capital-labor ratio than the primary sector (see Table 1 and Figure 8). Further, the increase in the share of the non-primary sector itself likely contributed to the TFP growth and the increase in the capital-labor ratio in the economy overall.

Table 1. Decomposition of labor productivity growth for the economy overall, the primary sector, and the non-primary sector: 1874-2015

Economy overall

\begin{tabular}{|c|c|c|c|c|c|c|c|}
\hline & $\begin{array}{l}\text { Labor } \\
\text { productivity } \\
\text { growth } \\
\text { (a) }\end{array}$ & $\begin{array}{l}\text { Contribution of } \\
\text { increases in } \\
\text { capital stock per } \\
\text { hour worked } \\
\text { (b) }\end{array}$ & $\begin{array}{l}\text { Contribution of } \\
\text { increases in } \\
\text { arable land per } \\
\text { hour worked } \\
\text { (c) }\end{array}$ & $\begin{array}{l}\text { Contribution of } \\
\text { labor quality } \\
\text { improvements } \\
\text { (d) }\end{array}$ & $\begin{array}{l}\text { TFP growth } \\
\text { (e=a-b-c-d) }\end{array}$ & $\begin{array}{c}\text { Increase in hours } \\
\text { worked } \\
\text { (f) }\end{array}$ & $\begin{array}{l}\text { GDP growth } \\
\qquad(\mathrm{g}=\mathrm{a}+\mathrm{f})\end{array}$ \\
\hline Early Meiji: $1874-1885$ & $1.14 \%$ & & & & & $0.36 \%$ & $1.51 \%$ \\
\hline Meiji I: 1885-1899 & $2.71 \%$ & $0.67 \%$ & $0.12 \%$ & $0.88 \%$ & $1.04 \%$ & $-0.40 \%$ & $2.31 \%$ \\
\hline Meiji II: 1899-1913 & $1.50 \%$ & $0.62 \%$ & $-0.02 \%$ & $0.52 \%$ & $0.38 \%$ & $0.76 \%$ & $2.26 \%$ \\
\hline Taisho: 1913-26 & $1.63 \%$ & $0.53 \%$ & $-0.14 \%$ & $1.26 \%$ & $-0.02 \%$ & $2.09 \%$ & $3.72 \%$ \\
\hline Prewar Showa: 1926-40 & $2.89 \%$ & $0.96 \%$ & $-0.04 \%$ & $0.59 \%$ & $1.38 \%$ & $0.95 \%$ & $3.84 \%$ \\
\hline War and postwar recovery: 1940-55 & $2.02 \%$ & $0.77 \%$ & $0.00 \%$ & $0.62 \%$ & $0.62 \%$ & $-1.14 \%$ & $0.88 \%$ \\
\hline High-speed growth: 1955-70 & $7.52 \%$ & $3.01 \%$ & $-0.03 \%$ & $1.33 \%$ & $3.21 \%$ & $2.30 \%$ & $9.82 \%$ \\
\hline Stable growth: $1970-90$ & $4.23 \%$ & $1.67 \%$ & & $0.76 \%$ & $1.80 \%$ & $0.50 \%$ & $4.73 \%$ \\
\hline Prolonged stagnation: 1990-2015 & $1.39 \%$ & $0.80 \%$ & & $0.31 \%$ & $0.28 \%$ & $-0.55 \%$ & $0.84 \%$ \\
\hline
\end{tabular}

Primary sector

\begin{tabular}{|c|c|c|c|c|c|c|c|}
\hline & $\begin{array}{l}\text { Labor } \\
\text { productivity } \\
\text { growth } \\
\text { (a) }\end{array}$ & $\begin{array}{l}\text { Contribution of } \\
\text { increases in } \\
\text { capital stock per } \\
\text { hour worked } \\
\text { (b) }\end{array}$ & $\begin{array}{l}\text { Contribution of } \\
\text { increases in } \\
\text { arable land per } \\
\text { hour worked } \\
\text { (c) }\end{array}$ & $\begin{array}{l}\text { Contribution of } \\
\text { labor quality } \\
\text { improvements } \\
\text { (d) }\end{array}$ & $\begin{array}{l}\text { TFP growth } \\
\text { (e=a-b-c-d) }\end{array}$ & $\begin{array}{l}\text { Increase in hours } \\
\text { worked } \\
\text { (f) }\end{array}$ & $\begin{array}{l}\text { GDP growth } \\
\qquad(\mathrm{g}=\mathrm{a}+\mathrm{f})\end{array}$ \\
\hline Early Meiji: $1874-1885$ & $0.93 \%$ & & & & & $-0.40 \%$ & $0.53 \%$ \\
\hline Meiji I: 1885-1899 & $1.79 \%$ & $0.15 \%$ & $0.48 \%$ & $0.39 \%$ & $0.77 \%$ & $-0.91 \%$ & $0.88 \%$ \\
\hline Meiji II: 1899-1913 & $1.32 \%$ & $0.12 \%$ & $0.06 \%$ & $0.32 \%$ & $0.82 \%$ & $0.47 \%$ & $1.80 \%$ \\
\hline Taisho: 1913-26 & $0.08 \%$ & $0.17 \%$ & $-0.12 \%$ & $0.59 \%$ & $-0.56 \%$ & $0.80 \%$ & $0.88 \%$ \\
\hline Prewar Showa: 1926-40 & $0.58 \%$ & $0.23 \%$ & $0.05 \%$ & $0.27 \%$ & $0.02 \%$ & $0.01 \%$ & $0.58 \%$ \\
\hline War and postwar recovery: 1940-55 & $2.15 \%$ & $0.31 \%$ & $-0.02 \%$ & $0.55 \%$ & $1.31 \%$ & $-1.35 \%$ & $0.80 \%$ \\
\hline High-speed growth: 1955-70 & $3.23 \%$ & $3.45 \%$ & $0.30 \%$ & $0.31 \%$ & $-0.83 \%$ & $-2.91 \%$ & $0.32 \%$ \\
\hline \multicolumn{8}{|l|}{ Stable growth: 1970-90 } \\
\hline Prolonged stagnation: 1990-2015 & & & & & & & \\
\hline
\end{tabular}

\section{Non-primary sector}




\begin{tabular}{|c|c|c|c|c|c|c|c|}
\hline & $\begin{array}{l}\text { Labor } \\
\text { productivity } \\
\text { growth } \\
\text { (a) }\end{array}$ & $\begin{array}{l}\text { Contribution of } \\
\text { increases in } \\
\text { capital stock per } \\
\text { hour worked } \\
\text { (b) }\end{array}$ & $\begin{array}{c}\text { Contribution of } \\
\text { increases in } \\
\text { arable land per } \\
\text { hour worked } \\
\text { (c) }\end{array}$ & $\begin{array}{l}\text { Contribution of } \\
\text { labor quality } \\
\text { improvements } \\
\text { (d) }\end{array}$ & $\begin{array}{l}\text { TFP growth } \\
\text { (e=a-b-c-d) }\end{array}$ & $\begin{array}{c}\text { Increase in hours } \\
\text { worked } \\
\text { (f) }\end{array}$ & $\begin{array}{c}\text { GDP growth } \\
(\mathrm{g}=\mathrm{a}+\mathrm{f}) \\
\end{array}$ \\
\hline Early Meiji: $1874-1885$ & $0.23 \%$ & & & & & $1.96 \%$ & $2.18 \%$ \\
\hline Meiji I: 1885-1899 & $2.70 \%$ & $0.81 \%$ & & $0.84 \%$ & $1.05 \%$ & $0.45 \%$ & $3.14 \%$ \\
\hline Meiji II: 1899-1913 & $1.27 \%$ & $0.78 \%$ & & $0.47 \%$ & $0.02 \%$ & $1.17 \%$ & $2.44 \%$ \\
\hline Taisho: 1913-26 & $1.13 \%$ & $0.13 \%$ & & $1.00 \%$ & $0.00 \%$ & $3.57 \%$ & $4.70 \%$ \\
\hline Prewar Showa: 1926-40 & $2.74 \%$ & $0.82 \%$ & & $0.33 \%$ & $1.59 \%$ & $1.75 \%$ & $4.49 \%$ \\
\hline War and postwar recovery: 1940-55 & $1.74 \%$ & $1.00 \%$ & & $0.51 \%$ & $0.24 \%$ & $-0.98 \%$ & $0.76 \%$ \\
\hline High-speed growth: 1955-70 & $7.22 \%$ & $2.68 \%$ & & $0.42 \%$ & $4.12 \%$ & $3.72 \%$ & $10.94 \%$ \\
\hline Stable growth: 1970-90 & & & & & & & \\
\hline Prolonged stagnation: 1990-2015 & & & & & & & \\
\hline
\end{tabular}

Source: Authors' calculation. For details on the source data, see Section 2 and Appendix 1.

Figure 6. The sources of labor productivity growth in the economy overall (by period, annual average rate): 1874-2015

Growth accounting for the economy overall: 1885-2015

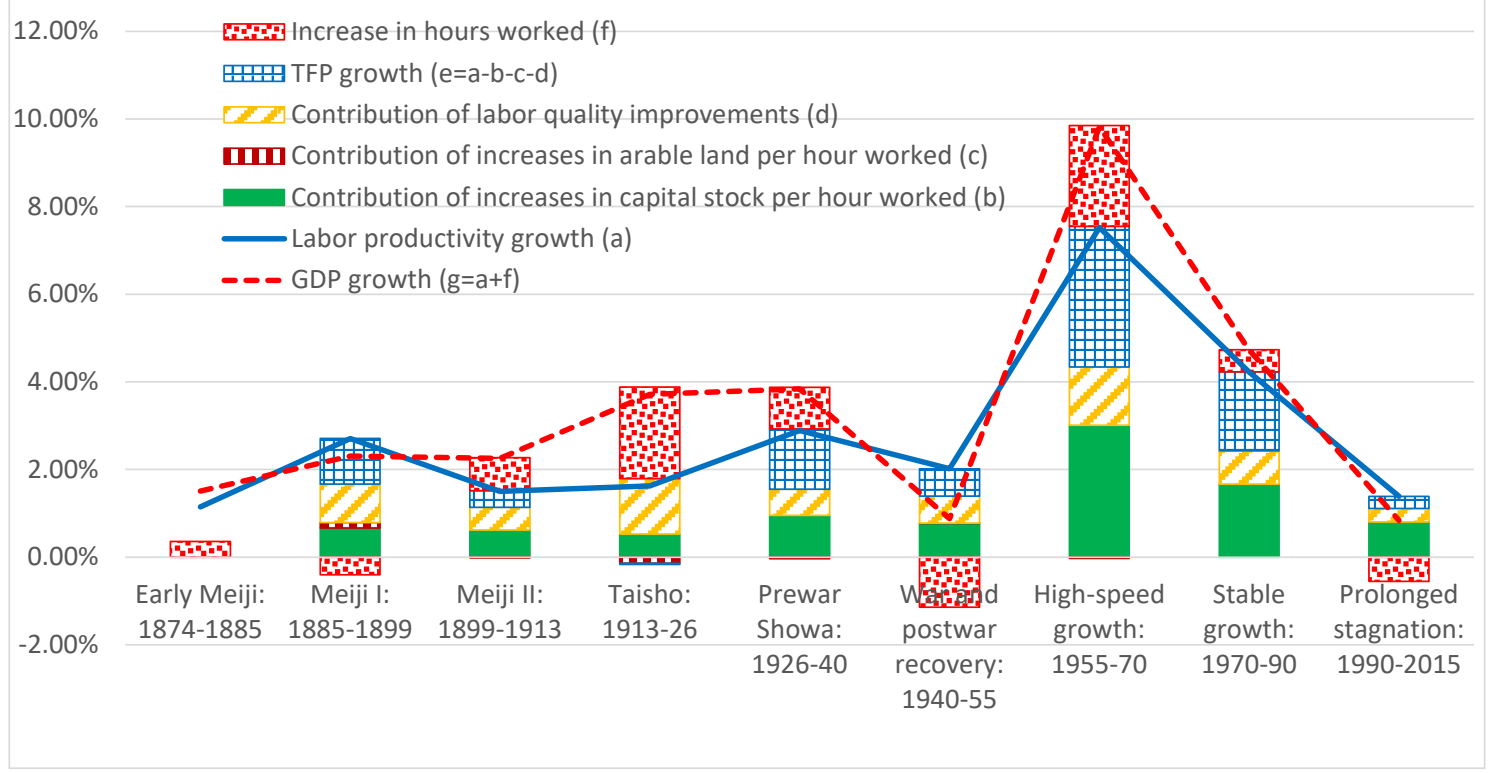

Source: See Table 1.

Figure 7. The sources of labor productivity growth in the economy overall (cumulative effect, natural logarithm): 1885-2015 


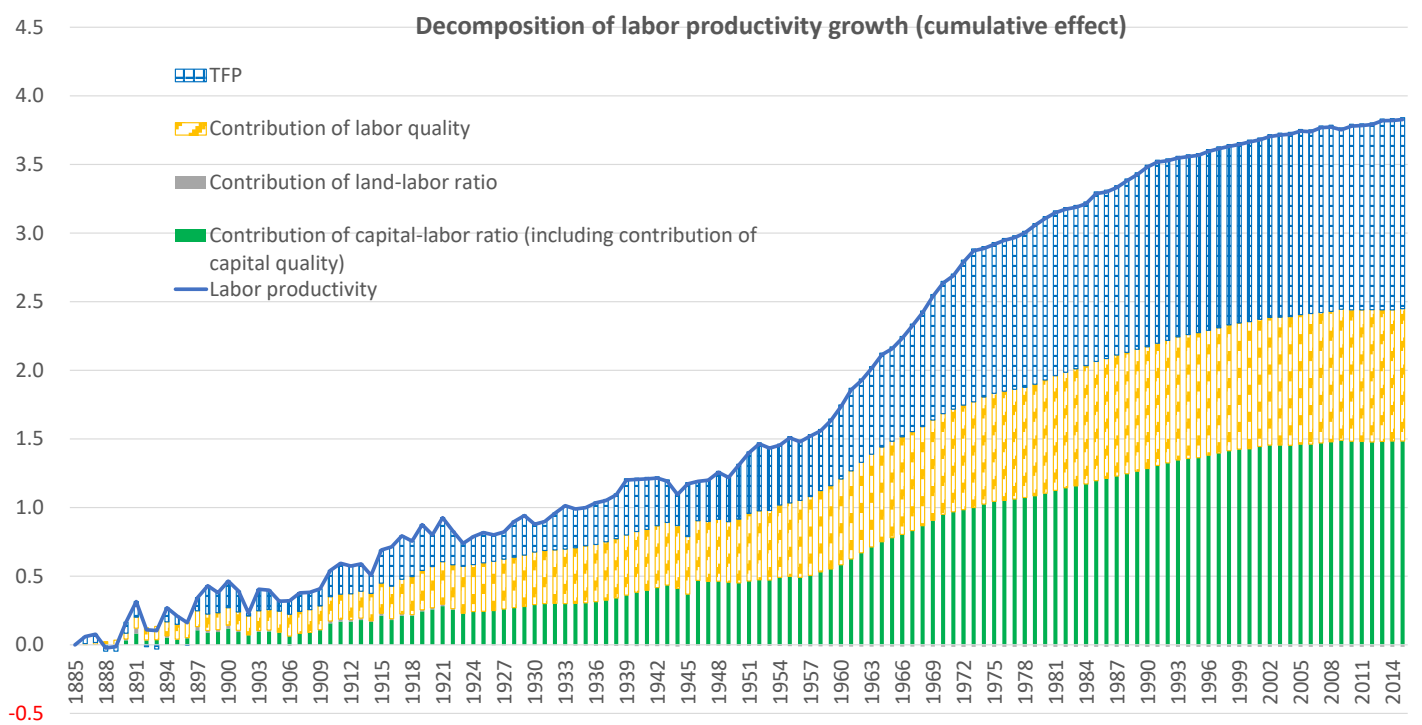

Source: See Table 1.

Figure 8. The sources of labor productivity growth in the primary and the non-primary sector (cumulative effect, natural logarithm): 1885-1970

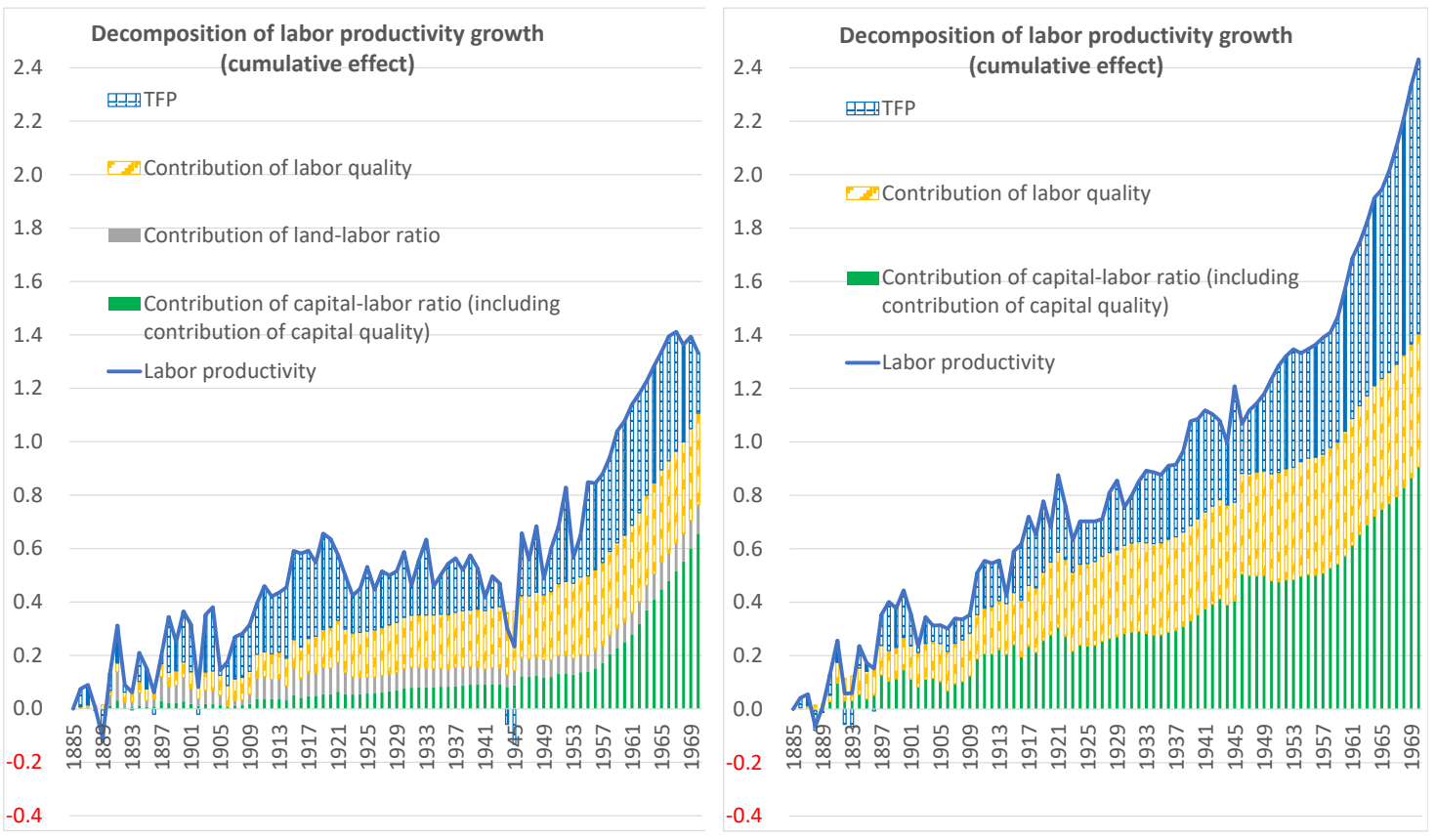

Source: See Table 1.

Figure 9. Share of the two sectors in total hours worked and in nominal GDP 


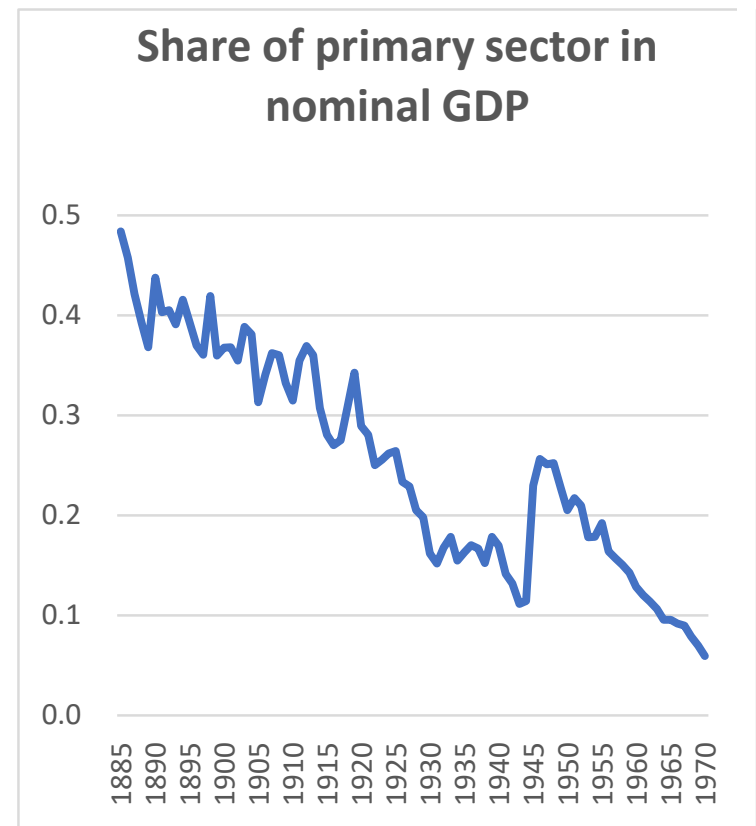

\section{Share of primary sector in total hours worked}

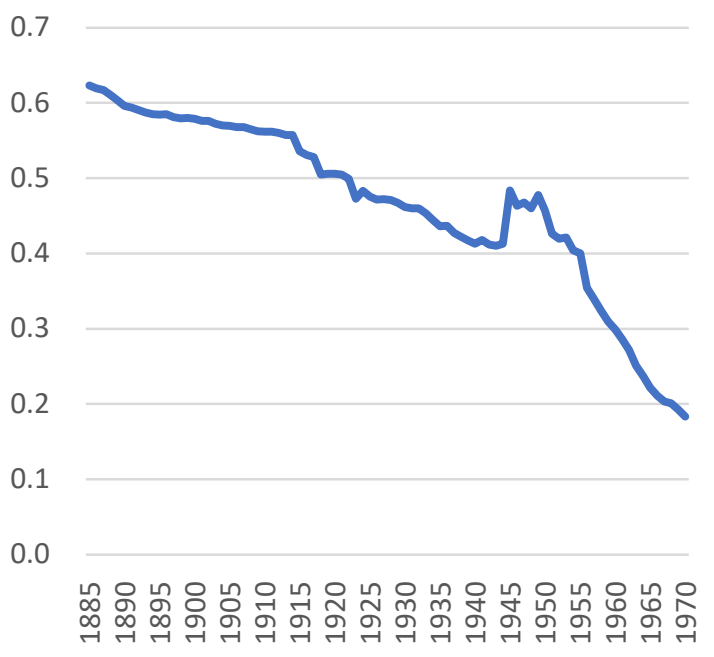

Source: See Table 1.

As we saw above, increases in labor quality have played an important role in Japan's economic growth. Specifically, increases in labor quality were responsible for 37 percent of the growth in labor productivity before 1940 and for 18 percent after 1955. As show by Equation (10) in the previous section, for the period before 1955, increases in labor quality in the economy overall can be divided into increases due to the reallocation of labor across industries (that is, the fact that the total hours worked of workers with particular characteristics increased more in industries paying higher wages) and rising education levels (measured in terms of the last school attended). The left panel of Figure 10 shows the results of this decomposition for the period up to 1940, for which reliable data are available. This figure shows the cumulative effect with regard to the natural logarithm of the labor quality index. The value of 0.77 for 1940 means that between 1885 and 1940, the level of labor quality increased 2.2 -fold $\left(2.72^{0.77}=2.2\right)$. It should be noted that the reason that the cumulative value (natural logarithm) of the contribution of labor quality growth in Figure 6 is smaller than the value in Figure 10 is that the former is multiplied by the labor share to calculate the contribution.

On the other hand, for the period from 1955 onward, as explained in the Appendix, we have data on hours worked and wages by educational attainment, industry, employment status, sex, and age. Focusing only on the educational attainment and industry among these characteristics would mean that we are throwing information away and therefore would be inappropriate. Consequently, in terms of worker characteristics, we conduct our decomposition regarding changes in wages resulting from changes in the industry in which workers are employed and changes in the employment status as 
measuring the reallocation effect ${ }^{8}$ and changes in wages due to changes in all other characteristics as reflecting labor quality growth due to factors other than the reallocation of labor across industries. The results are shown in the right-hand panel of Figure 10.

Figure 10. Decomposition of labor quality growth (natural log; cumulative effect): 1885-1940 and 1955-2015
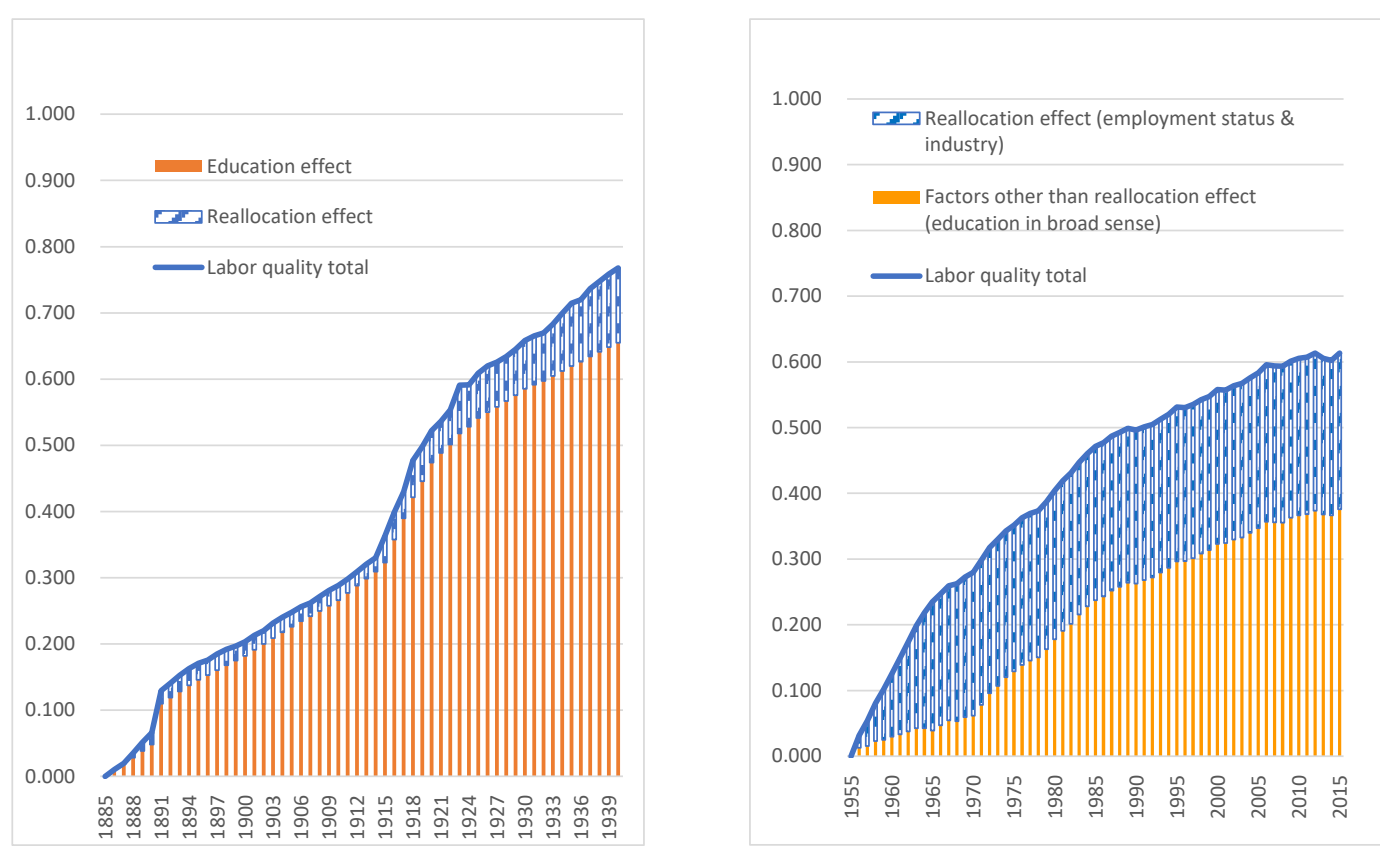

Source: See text.

The reason for including the employment status effect in the reallocation effect is as follows. In the non-primary sector, compensation for self-employed and unpaid family workers is quite low (for details of how we estimate compensation for self-employed and unpaid family workers, see chapter 1 of Fukao and Miyagawa, 2008). Most workers in the primary sector are self-employed or unpaid family workers. Therefore, if we assumed that the employment status remained unchanged when measuring the reallocation effect of a reduction in hours worked in the primary sector, we would likely

\footnotetext{
${ }^{8}$ We should note that we include the cross-term of changes in the distribution of hours worked across industries and changes in the distribution in terms of the employment status in the reallocation effect. The reason is as follows. Wage differentials across industries differ depending on the employment status. As a result, the impact on labor quality of joint changes in hours worked by industry and employment status depends on the covariance of changes in the industry distribution of hours worked and changes in the employment status distribution of hours worked, that is, in what industry there were particularly large changes in the number of workers with a particular employment status. We therefore include the cross-term of changes in the distribution of hours worked across industries and in the distribution in terms of the employment status in the reallocation effect. In Equation (10), only workers' industry and educational attainment are considered as worker characteristics; however, when we decompose data on worker characteristics with more than two dimensions, the decomposition equation becomes more complex. For more details, see Jorgenson, Gollop, and Fraumeni (1987).
} 
underestimate the redistribution effect. For example, if a large number of workers leaving farming find work as employees, the effect of the change in their job status should be regarded as part of the reallocation effect.

In the analysis for the period from 1955 onward, the effect of "labor quality improvements other than through the reallocation of labor across industries” includes the effects of educational attainment, age, and sex. In the following, we will regard this as representing the effect of education in a broader sense. In the case of age, the rationale is straightforward: assuming that seniority wages - a key element of Japanese-style employment practices - partly reflect the accumulation of skills, this accumulation of skills can be regarded as education in a broad sense. On the other hand, it is unlikely that the effect of the composition of workers by sex reflects the effect of education. To examine how much of an issue including sex in the education effect is, we estimate for 1955-2015 how much of the increase in labor quality is due to changes in the sex composition of workers. Looking at the cumulative effect (natural logarithm) from 1955 onward, the effect of changes in the sex composition of workers recorded a peak value of 0.022 in 1965 . This is likely due to the fact that the share of hours worked of men, who tend to earn higher wages than women, increased up until this point in time; however, this effect increased labor quality only by 2.2 percent $\left(2.72^{0.022}=1.022\right)$. Since then, this effect has been declining, reflecting the increase in women's share in total hours worked, so that the increase in labor quality from 1955 to 2015 due to changes in the sex composition of workers amounts to only by 1.5 percent. Therefore, even if we regard the effect of changes in the sex composition as part of the education effect it is unlikely to cause any major distortions.

In order to understand the labor reallocation effect, we calculate the relative wage $w_{A} / w_{N}$ between the two sectors adjusted for labor quality differences (the nominal wage per hour in the primary sector setting the nominal wage in the non-primary sector to 1 ). The result is shown in Figure 11. For the prewar period, we use the following estimation approach, which is widely used when making international comparisons of wages adjusted for labor quality differences (see O’Mahony and Timmer 2009):

$$
\ln \left(\frac{w_{A}}{w_{N}}\right)=\sum_{j}\left\{\left(\frac{w_{A, j} H_{A, j}}{\sum_{j \prime} w_{A, j} H_{A, j \prime}}+\frac{w_{N, j} H_{N, j}}{\sum_{j \prime} w_{N, j^{\prime}} H_{N, j}}\right) \ln \left(\frac{w_{A, j}}{w_{N, j}}\right)\right\}
$$

Unfortunately, for the period from 1955 onward, for which data by employment status are available, data for the educational attainment the self-employed and unpaid family workers are not available, so that we cannot estimate wage differentials based on the above equation. In Figure 11, we therefore present two relative wage series for the high-speed growth era. Series A compares the hourly wage of 
male primary sector self-employed workers (including family workers) aged 40-49 years of all education levels on the one hand and male non-primary sector employed workers aged 40-49 years that are high-school graduates. Series A assumes that, in the primary sector, the remuneration of selfemployed workers and unpaid family workers working with these self-employed workers is identical, so that it is highly likely that the remuneration of self-employed workers is underestimated. We therefore also prepared Series B, in which the relative wage is calculated assuming that the labor remuneration of family employees is zero and their earnings are included in the remuneration of the self-employed. The actual wage differential probably lies somewhere between Series A and Series B. We calculate the relative wage for 1955, 1960, 1965, and 1970 for the high-speed growth period and filled in values for intervening years assuming that the relative wage changed at a constant pace.

The relative wage in the primary sector compared to that in the non-primary sector fell substantially in the 1930s, probably reflecting the decline in global primary commodity prices in the wake of the Great Depression as well as Japan's industrialization in the heavy and chemical industries in the 1930s. In the high-speed growth period, the wage differential further increased reflecting the rapid rise in labor productivity in the non-primary sector.

For the prewar period, we can calculate how much the education quality in the labor input in the two sectors differed by dividing the total labor cost ratio between the two sectors by the labor qualityadjusted wage ratio calculated as just described (this approach is also widely used in international comparisons). Figure 12 presents the result, which indicates that relative to the non-primary sector, the education level of labor input in the primary sector declined rapidly, so the gap in labor quality with respect to the education level widened.

As shown in Figure 10, most of the increase in labor quality up to 1940 was due to the effect of education. The reason why the labor reallocation effect was small likely is the slow shift of labor input from the primary to the non-primary sector, as seen in Figure 4 . The share of the primary sector in the total hours worked in the economy overall declined only about 20 percentage points in the 55 years from 1885 to 1940. Meanwhile, looking at the education-adjusted wage differential between the two sectors, wages in the primary sector in the prewar period were about 60 percent lower than in the nonprimary sector, as shown in Figure 11.

The reason that the education effect was substantial is that, as seen in the previous section, the percentage of workers with elementary education increased quickly following the introduction of compulsory education in 1872; moreover, the average years of schooling increased rapidly as the number of workers that received this new education rose due to the growing population. 
Looking at the 55 years from 1885 to 1940 in more detail, in the subperiod after World War I, the service sector absorbed much of the increased population, and the decline in the share of the primary sector accelerated. Meanwhile, output in the heavy and chemical industries increased rapidly due to the disruption of imports to Asia from Europe due to World War I, the rise of protectionist trade policies in Japan due to the restoration of tariff autonomy since the end of the 19th century, the development of the war economy since the 1930s, and other factors. Moreover, in the 1920s, capital-intensive public utilities such as power supply expanded. These factors led to a decline in the relative labor productivity and relative wage in the primary sector vis-à-vis the non-primary sector. As the second term in the square brackets on the right-hand side of Equation (10) shows, the faster the industrial structure changes and the greater the labor quality-adjusted wage gap between the two industries, the greater is the reallocation effect. The rapid increase in the labor reallocation effect after World War I seen in Figure 10 likely was caused by such changes in the economic structure.

During the high-speed growth period from 1955 to 1970, labor quality growth was mainly caused by the reallocation effect (the industry and employment status effects). One of the main reasons is that the share of the primary sector in the total hours worked in the economy overall fell by about 20 percentage points during this period. In terms of the share of hours worked, a contraction of the primary sector of almost the same size as during the 55 years from 1885 to 1940 occurred in the 15 years of the high-speed growth era. On the other hand, the laborquality-adjusted wage gap was even greater during the high-speed growth period than before 1940 (see Figure 11). It is likely that the rapid shrinking of the primary sector and the large wage differential played a key role in the large reallocation effect during the high-growth period. It should be noted, however, that for the high-speed growth era, the reallocation effect is calculated using data for 24 industries. During this period, highwage industries within the non-primary sector expanded and the share of self-employed and unpaid family workers declined, which likely further increased the reallocation effect.

On the other hand, in the period from 1970 onward, the education effect in a broader sense was the driving force of increases in labor quality, as can be seen in Figure 10. The likely reason is that while the outflow of labor from the primary sector became more gradual, reducing the reallocation effect (the industry and employment status effects), the education and age effects increased due to the rising share of workers that had attended high school and/or university and the fact that the baby boomer generation was gradually growing older under the seniority wage system. Meanwhile, the increase in the share of nonregular workers in recent years lowered the annual average growth rate of the labor quality index by 0.19 percentage points in the period $1970-1990$ and 0.16 percentage points in the 
period 1990-2015. ${ }^{9}$ This is also one of the reasons why the reallocation effect (the industry and employment status effects) has made such a small contribution since the 1970s.

Figure 11. Wage differential between the two sectors adjusted for labor quality differences due to education (Primary sector wage level setting the wage level in the non-primary sector to 1 )

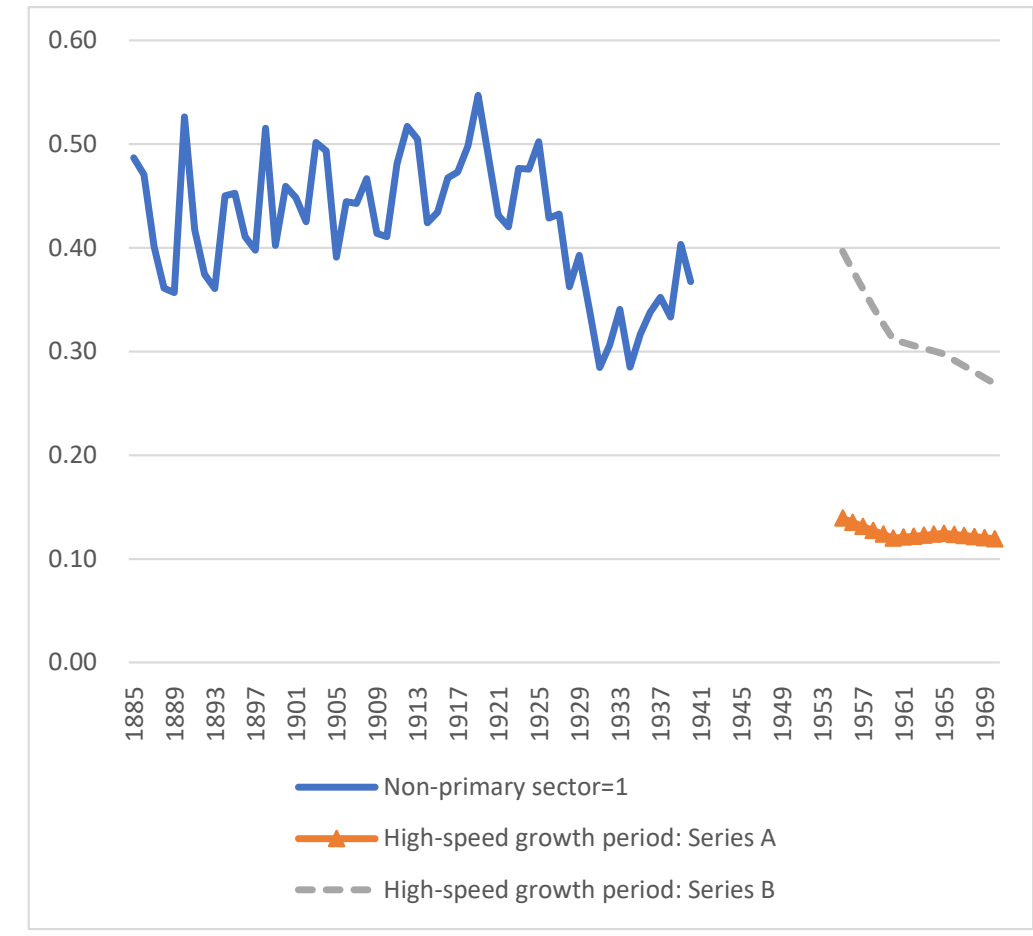

Source: See main text for details on how the data were constructed.

Figure 12. Developments in the education level in the primary sector relative to the nonprimary sector (Non-primary sector $=1)$ 9 These values are calculated using JIP Database 2015 for the period 1970-1995 and JIP Database 2018 for
the period of 1995-2015. 


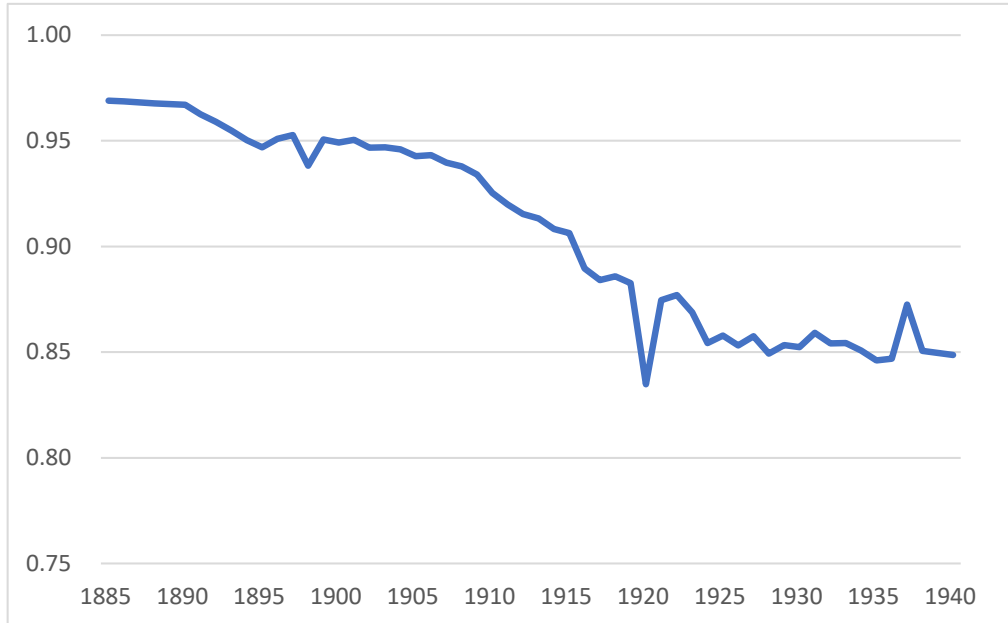

Source: See main text for details on how the data were constructed.

As described in Section 2, in our analysis, the level of detail of worker characteristics captured in the data differs before and after World War II. This may overstate the reallocation effect in the postwar period. In order to examine this point, we create labor data for 1955-1970 using the classifications for the prewar period to calculate the increase in labor quality. ${ }^{10}$

Figure 13 shows the result of this calculation. Comparing this to Figure 10, we can see that, as expected, the labor reallocation effect is much smaller when we classify worker characteristics in line with the coarser prewar categories. On the other hand, there is almost no change in the education effect. As a result, the cumulative effect (logarithmic value) of the increase in labor quality in 1955-70, which combines the two effects, is only 41 percent $(0.115 / 0.280=0.41)$ of the effect in Figure 10 .

Given that in growth accounting analyses it is desirable to use detailed data for worker characteristics in order to make the residual TFP as small as possible, we consider the results in Figure 10 as the baseline. However, the estimation results in Figure 13 suggest that there is a risk that the

${ }^{10}$ Broadly speaking, we constructed the data as follows. (1) Because, the 1970 Population Census, unlike the 1960 Population Census, does not provide population data by age, educational attainment, and urban/rural area, we use the number of employees by age, educational attainment, and primary/non-primary sector. (2) As for the number of employees by educational attainment by primary/non-primary sector in 1955, 1960, and 1965, we use information on the number of employees by age from the 1970 Population Census and extrapolate backward without matching the results with the 1960 Population Census. (3) Like for the period before World War II, we do not distinguish between self-employed/family workers and employees either in the primary or the non-primary sector and assume that the wages of selfemployed/family workers and employees are identical. (4) We set the wages of employees that graduated from junior high school (corresponding to elementary school graduates in the prewar classification) for both the primary and non-primary sector as the reference and use the wage gaps in the non-primary sector vis-à-vis high school graduates (secondary education in the prewar classification) and technical college, junior college, and university graduates (tertiary education in the prewar classification) also for the primary sector. Moreover, we assume that the wages of those without schooling are the same as the wages of junior high school graduates. 
results for the prewar period, for which only coarse classifications are available, underestimate the labor reallocation effect.

\section{Figure 13. Decomposition of labor quality when assuming that the classification of worker characteristics is the same as before World War II (natural logarithm; cumulative effect): 1955-1970}

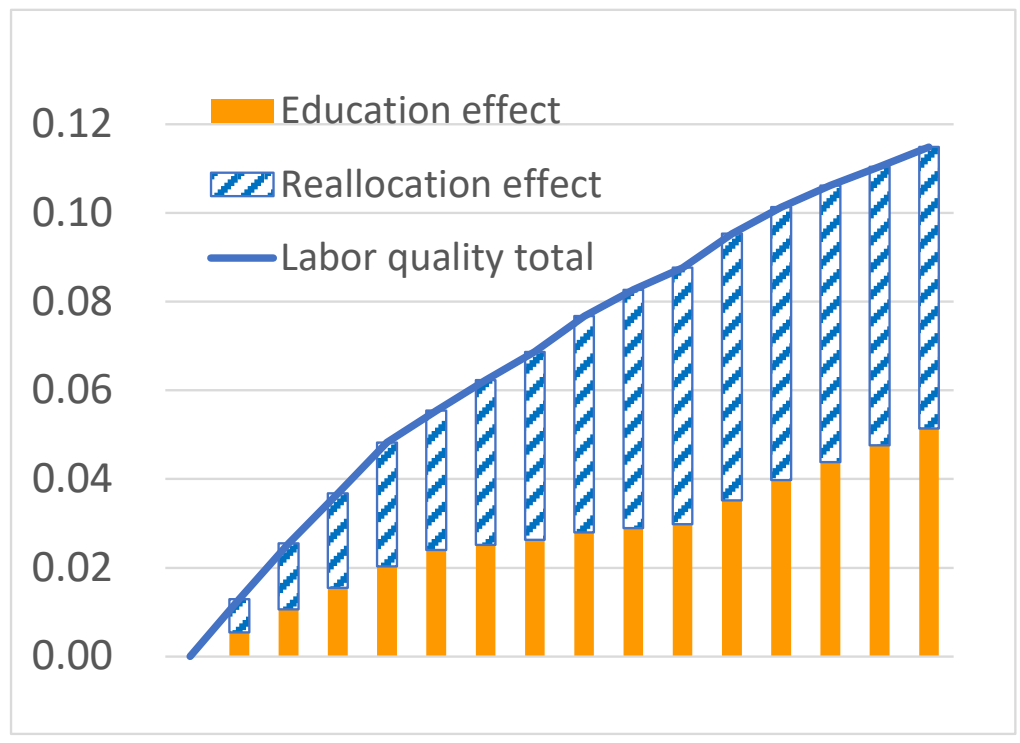

Source: See text.

\section{Conclusion}

This study presented growth account for Japan for the 130 years from 1885 to 2015 based on the measurement of labor quality simultaneously taking the effects of education and the allocation of labor across industries into account. The estimation results indicate that, over the 130 years, Japan's labor productivity rose 46 -fold, with increases in the capital-labor ratio accounting for 40 percent of this rise, improvements in labor quality for 35 percent, and TFP growth for 36 percent (Figure 2). Looking at the periods before and after World War II separately, we found that labor productivity growth accelerated substantially in the postwar period and was twice as high as in the prewar period. This difference in labor productivity growth can be explained by differences in the sources of growth: while growth during the prewar period was driven mainly by improvements in labor quality (with a growth contribution of 37 percent), during the postwar period increases in the capital-labor ratio and TFP growth made the largest contribution (38 percent and 35 percent, respectively).

In the prewar period, labor quality increased 2.4-fold between 1885 and 1940, most of which was 
due to the effect of education. Reasons for this increase likely include the steep rise in enrolment rates following the introduction of compulsory education as well as the rapid increase in the average years of schooling. Thus, while government policies following the Meiji Restoration to promote industry, such as the import of large-scale spinning machinery with 2000 spindles, do not appear to have borne much fruit, education policy made a major contribution to Japan's economic growth. On the other hand, the labor reallocation effect was relatively small due to the slow movement of labor from the primary sector into the non-primary sector. However, after World War I, the movement of labor into the non-primary sector accelerated and the wage gap between the non-primary and primary sectors (controlled for education) increased, so that the reallocation effect played a larger role. These trends further accelerated after World War II, and until 1970 the contribution of the reallocation effect to labor quality growth rapidly increased (Figure 10). However, from 1970 onward, the effect of education in a broader sense again appears to have been the driving force of labor quality growth. The likely reason is that the movement of labor from the primary to the non-primary sector had passed its peak and the reallocation effect was diminishing, while the effect of education in a broader sense increased as a result of rising high-school and university enrolment rates and the aging (and hence skill accumulation) of the baby-boomer generation.

Comparing Japan's experience with that of other countries suggests that the introduction of an education system appears to have gone more smoothly and spread more widely than in other countries, so that by 1935, Japan - despite its relatively low per capita GDP - had exceptionally high average years of schooling. Further, although secondary education enrolment rates increased rapidly after World War II, tertiary enrolment rates even today have not caught up with the level of the United States. The rapid spread of education during the prewar period substantially contributed to the rapid labor productivity growth at an annual rate of 2.2 percent from 1885 to 1940. Moreover, during the high-speed growth era, Japan experienced prolonged labor productivity growth at an unprecedented annual rate of 7 percent. Although the main sources of that growth were increases in TFP and the capital-labor ratio, increases in labor quality through structural change also made a substantial contribution to labor productivity growth during this period.

As shown in this study, labor quality improvements played a major role in Japan's long-term economic growth. However, the mechanism through which labor quality growth contributed to productivity growth differed from period to period, with rising education levels being the main driver before the war and in the period after 1970, while during the high-speed growth era it did so via the reallocation effect. Japan's experience shows that both raising education levels and promoting smooth structural change can be effective means of achieving economic growth. 


\section{Appendix: Data used for the growth accounting}

This appendix provides additional details on the data construction not fully covered in Section 2.

Data for the period before 1955

Data for nominal and real GDP, the number of employees, and land are essentially taken from Fukao, Settsu, and Nakabayashi (2018) and Fukao and Settsu (2018a), and details of the data construction can be found in those studies. The following therefore briefly describes revisions and new additions to the data from those two studies.

For the income shares of labor and capital in the non-primary sector, Fukao, Settsu, and Nakabayashi (2018) and Fukao and Settsu (2018a) used the estimates by Minami and Ono (1975) without any changes. The income shares Minami and Ono (1975) estimated are the labor and capital income shares of domestic factor income in the non-primary sector, and fixed capital depreciation is not included in the calculation of the capital income share. On the other hand, in this study, we regard the share of labor income and capital income (including fixed capital depreciation) in the gross domestic product of the non-primary sector as the labor and capital income shares. Therefore, if we were to use Minami and Ono's (1975) income share estimates, our estimates of the growth contributions of labor and capital input and TFP growth would be incorrect. Consequently, we decided to revise the labor and capital income shares using the following approach.

Let us start by explaining our approach for the period up to 1940. First, we subtract nominal depreciation in agriculture, forestry, and fisheries from the nominal depreciation the economy overall estimated by Ohkawa et al. (1974) to obtain nominal depreciation for the non-primary sector. Next, we obtain the nominal net domestic product by subtracting nominal depreciation from the nominal gross domestic product of the non-primary sector and multiply this by the labor and capital income shares from Minami and Ono (1975) to obtain labor and capital income (excluding the depreciation of fixed capital). Finally, we add depreciation to this capital income, regard this as the adjusted capital income, and calculate the labor and capital income shares using the adjusted capital income and the labor income obtained earlier. For the period from 1940 onwards, we use the nominal depreciation rate for the non-primary sector taken from Keizai Shingicho (1954) and national income statistics to calculate the labor and capital income shares using the same process as for the period up to 1940 . Meanwhile, the income shares in the primary sector are estimated based on the method of Hayami (1973), and since capital income includes the depreciation of fixed capital - albeit based on a very simple approach - we did not make a similar adjustment for the non-primary sector. 
Hours worked up to 1940 are estimated as explained in Section 2 of the main text. Hours worked in the non-primary sector from 1941 to 1944 are calculated from the average daily hours worked and actual days worked of factory workers taken from the Roudou Toukei Maitsuki Jicchi Chosa (the Monthly Surveys of the Labour Statistics)," while for 1947 to 1954, we use the total actual working hours in all the industries surveyed from the Monthly Labour Survey. For 1945 and 1946, for which data are not available, we proceed as follows. For 1946, we extrapolate backward using the rate of change from 1947 to 1948, while for 1945 we use 7/12 of the value for 1944 and 5/12 of the value for 1946. For the primary sector, we multiply the primary/non-primary sector ratio for the period 1940 by the estimates of hours worked in the non-primary sector.

Labor quality up to 1940, like hours worked, is estimated as described in Section 2 of the main text. For the period from 1940 to 1955, sufficient data that would allow us to estimate labor quality using either the methodology up to 1940 or that from 1955 are not available. However, for the years 1940 and 1955, we can construct data on educational attainment, wages, hours worked, and the number of employees for the primary and the non-primary sector. Therefore, using the data for 1940 and 1955, we obtain the period average growth rate of labor quality in the primary and the non-primary sector employing the approach used for the period up to 1940. Next, we adjust the annual series of the labor reallocation effect from Fukao, Makino, and Settsu (2019) to make it consistent with this annual average growth rate over the period 1940-1955 and use this as the annual series of the labor quality index for the period 1940-1955.

It is even more difficult to obtain data for measuring the quality of capital than the quality of labor, so that for the entire period before 1955 we used the estimates of the capital reallocation effect obtained by Fukao, Makino and Settsu (2019). This means that we cannot take into account improvements in the quality of capital in the primary and the non-primary sector.

Data for the period from 1955 onward

For the period from 1955 to 1970, we take our main data from Fukao and Settsu (2018b). We newly estimate data on hours worked, which were not included in Fukao and Settsu (2018b), constructing annual series by industry from the Labour Force Survey, the Monthly Labour Survey, etc. For labor quality, we newly construct data on the number of employees, hours worked, and labor income by worker characteristics from the Basic Survey on Wage Structure, the Population Census, the Employment Status Survey, etc., and like in the JIP 2015 and JIP 2018 estimate labor quality using Jorgensen et al.’s (1987) approach. Worker characteristic are classified as follows. 


\begin{tabular}{|l|l|}
\hline Sex (2) & Male, female \\
\hline Employment status (2) & Self-employed/family worker; employee \\
\hline Age (8) & $\begin{array}{l}\text { 15-19 years old; 20-24 years old; 25-29 years old; 30-34 years old; 35-39 } \\
\text { years old; 40-49 years old; 50-59 years old; and over 60 years old }\end{array}$ \\
\hline Educational attainment (4) & $\begin{array}{l}\text { Junior high school; high school; technical/junior college; university } \\
\text { (For the self-employed/family workers, no classification by schooling is } \\
\text { available, while women are classified into the two groups of junior high } \\
\text { school and high school or higher.) }\end{array}$ \\
\hline Industry (24) & $\begin{array}{l}\text { Agriculture, forestry, and fisheries; mining; food; textiles; pulp and paper; } \\
\text { chemicals; petroleum and coal products; ceramic, stone, and clay products; } \\
\text { primary metal; metal products; general machinery; electrical machinery; } \\
\text { transportation equipment; precision machinery; other manufacturing; } \\
\text { construction; electricity, gas, and water; wholesale and retail; finance and } \\
\text { insurance; real estate; transportation and communication; services (private, } \\
\text { not for profit); services (government); housing (owned housing) } \\
\text { (Housing refers to imputed rent and the number of employees is zero.) }\end{array}$ \\
\hline
\end{tabular}

For the period from 1970 to 1995, we used the JIP 2015, while for the period from 1995 onward we used the JIP 2018. For details on the way the data in the JIP Database were estimated, see Fukao and Miyagawa (2008, Chapter 1) and the JIP Database 2018 website (https://www.rieti.go.jp/en/database/JIP2018/index.html). As mentioned in the main text, the JIP 2015 is based on the 1993 SNA, while the JIP 2018 is based on the 2008 SNA. Moreover, the above data for 1955-1970 are based on the 68 SNA. It should therefore be noted that we linked the data without making any adjustments for the changes in SNA standards. 


\section{References}

Bakker, Gerben, Nicholas Crafts, and Pieter Woltjer (2019) “The Sources of Growth in a Technology Progressive Economy: The United States, 1899-1941,” The Economic Journal, Vol. 129, No. 622, pp. 2267-2294.

Crafts, Nick (2019) "The Sources of British Economic Growth Since the Industrial Revolution: Not the Same Old Story,” CAGE Online Working Paper Series 430, Competitive Advantage in the Global Economy (CAGE), University of Warwick.

Denison, Edward F. (1962) The Sources of Economic Growth in the United States and the Alternatives Before Us, New York: Committee for Economic Development.

Fukao, Kyoji (2012) 'Ushinawareta 20-nen' to Nihon Keizai: Kozo-teki Genin to Saisei he no Gendoryoku no Kaimei [The Structural Causes of Japan's 'Two Lost Decades': Forging a New Growth Strategy], Tokyo: Nikkei Publishing Inc. (in Japanese).

Fukao, Kyoji, Sumio Hamagata, Tomohiko Inui, Keiko Ito, Hyeog Ug Kwon, Tatsuji Makino, Tsutomu Miyagawa, Yasuo Nakanishi, Joji Tokui (2007) “Estimation Procedures and TFP Analysis of the JIP Database 2006,” RIETI Discussion Paper, No. 07-E-003.

Fukao, Kyoji, Tatsuji Makino, and Tokihiko Settsu (2019) “Structural Change, Capital Deepening, and TFP Growth in Japan: 1885-1970,” Discussion Paper Series A, No. 693, Institute of Economic Research, Hitotsubashi University.

Fukao, Kyoji and Tsutomu Miyagawa, eds. (2008) Seisansei to Nihon no Keizai Seicho: JIP Database ni yoru Sangyo/Kigyo Reberu no Jissho Bunseki [Productivity and Japan's Economic Growth: An Empirical Analysis at the Industry and Firm Level Based on the JIP Database], University of Tokyo Press (in Japanese).

Fukao, Kyoji and Tokihiko Settsu (2018a) "Kanmatsu Furoku: Seisan, Bukka to Shotoku no Suikei [Appendix Tables: Estimation of Production, Prices, and Income,” in Kyoji Fukao, Naofumi Nakamura and Masaki Nakabayashi, eds., Iwanami Koza: Nihon Keizai no Rekishi 4, Kindai 2 [History of the Japanese Economy, Iwanami Lecture Series, Vol. 4, The Contemporary Period 2], Iwanami Shoten (in Japanese).

Fukao, Kyoji and Tokihiko Settsu (2018b) "Kanmatsu Furoku: Seisan, Bukka to Shotoku no Suikei [Appendix Tables: Estimation of Production, Prices and Income],” in Kyoji Fukao, Naofumi Nakamura and Masaki Nakabayashi, eds., Iwanami Koza: Nihon Keizai no Rekishi 5, Gendai 1 [History of the Japanese Economy, Iwanami Lecture Series, Vol. 5, The Contemporary Period 1], Iwanami Shoten (in Japanese).

Fukao, Kyoji, Tokihiko Settsu, and Masaki Nakabayashi (2018) "Kanmatsu Furoku: Seisan, Bukka to Shotoku no Suikei [Appendix Tables: Estimation of Production, Prices, and Income,” in Kyoji Fukao, Naofumi Nakamura and Masaki Nakabayashi, eds., Iwanami Koza: Nihon Keizai no 
Rekishi 3, Gendai 1 [History of the Japanese Economy, Iwanami Lecture Series, Vol. 3, The Contemporary Period 1], Iwanami Shoten (in Japanese).

Godo, Yoshihisa and Yujiro Hayami (2002) "Catching Up in Education in the Economic Catch-Up of Japan with the United States, 1890-1990,” Economic Development and Cultural Change, Vol. 50, No. 4, pp. 961-78.

Hayami, Yujiro (1973) Nihon Nogyo no Seicho Katei [The Growth Process of Japanese Agriculture], Sobunsha (in Japanese).

Japan Statistical Association (2006) Shinpan: Nihon Choki Tokei Soran [Historical Statistics of Japan:

New Edition], Japan Statistical Association (in Japanese).

Jorgenson, Dale W. (1995) Productivity: Postwar U.S. Economic Growth, MIT Press.

Jorgenson, Dale W., Frank M. Gollop, and Barbara M. Fraumeni (1987) Productivity and U.S.

Economic Growth, Cambridge, MA: Harvard University Press.

Jorgenson, Dale, Mun S. Ho, Jon D. Samuels, and Kevin J. Stiroh (2007) "Industry Origins of the American Productivity Resurgence,” Economic Systems Research, Vol. 19, No. 3, pp. 229-252. Jorgenson, Dale W., Koji Nomura, and Jon D. Samuels (2015) “A Half Century of Trans-Pacific Competition: Price Level Indices and Productivity Gaps for Japanese and U.S. Industries, 19552012,” in Dale W. Jorgenson, Kyoji Fukao, and Marcel P. Timmer, eds., Growth and Stagnation in the World Economy, Cambridge: Cambridge University Press.

Kendrick, John W. (1961) Productivity Trends in the United States, Princeton University Press.

Lee, Jong-Wha and Hanol Lee (2016) "Human Capital in the Long Run,” Journal of Development Economics, Vol. 122, pp. 147-169.

Keizai Shingicho, Kokumin Shotokuka [National Accounts Division, Economic Council Agency] (1954) Nihon Keizai to Kokumin Shotoku: Showa 5-nen-27-nen Kokumin Shotoku to Kokumin Keizai Keisan [Japan’s Economy and National Income: 1930-1952 National Income and National Accounts], Gakuyo Shobo (in Japanese).

Minami, Ryoshin and Akira Ono (1975) "Hi-ichiji Sangyo no Yoso Shotoku to Bunpai Ritsu [Factor Income and Distribution in Non-Primary Industry," in Kazushi Ohkawa and Ryoshin Minami, eds., Kindai Nihon no Keizai Hatten: 'Choki Keizei Tokei' ni yoru Bunseki' [Economic Development in Pre-Modern Japan, Analysis Based on the 'Long-Term Economic Statistics of Japan'], Toyo Keizai (in Japanese).

Nihon Hoso Kyokai [Japan Broadcasting Corporation] (1990) Kokumin Seikatsu Jikan Chosa: Showa 16-nen Chosa [National Time Use Survey: 1941], reprint, Ozorasha Shuppan.

Nihon Rodo Undo Shiryo Iinkai [Japan Labor Movement Historical Documents Committee] (1959) Nihon Rodo Undo Shiryo, Dai-10-kanu [Historical Documents of the Japanese Labor Movement, Vol. 10], Labor Movement Historical Documents Publication Committee.

Ohkawa, Kazushi, Tsutomu Noda, Nobukiyo Takamatsu, Saburo Yamada, Minoru Kumazaki, Yuichi 
Shionoya, and Ryoshin Minami (1967) Bukka [Prices], Long-Term Economic Statistics of Japan, Vol. 8, Toyo Keizai (in Japanese).

Ohkawa, Kazushi and Henry Rosovsky (1973) Japanese Economic Growth: Trend Acceleration in the Twentieth Century, Stanford University Press.

O’Mahony, Mary and Marcel P. Timmer (2009) “Output, Input and Productivity Measures at the Industry Level: the EU KLEMS Database,” Economic Journal, Vol. 119, No. 538, pp. F374F403.

Okazaki, Yoichi (1986) “Meiji Taisho-ki ni okeru Nihon Jinko to sono Dotai [Japan’s Population and Its Dynamics During the Meiji and Taisho Periods]," Jinko Mondai Kenkyu [Journal of Population Problems], Vol. 178, National Institute of Population and Social Security Research. Sonobe, Tetsushi and Keijiro Otsuka (2001) “A New Decomposition Approach to Growth Accounting: Derivation of the Formula and Its Application to Prewar Japan,” Japan and the World Economy, Vol. 13, pp. 1-14.

Solow, Robert M. (1957) “Technical Change and the Aggregate Production Function,” The Review of Economics and Statistics, Vol. 39, No. 3, pp. 312-320.

Umemura, Mataji, Keiko Akasaka, Ryoshin Minami, Nobukiyo Takamatsu, Kurotake Arai, Shigeru Itoh (1988) Rodoryoku [Manpower], Long-Term Economic Statistics, Vol. 9, Toyo Keizai (in Japanese).

Umemura, Mataji, Saburo Yamada, Yujiro Hayami, Nobukiyo Takamatsu, and Minoru Kumazaki (1966) Noringyo [Agriculture and Forestry], Long-Term Economic Statistics of Japan, Vol. 9, Toyo Keizai (in Japanese). 